\title{
Power Flow Control and Network Stability in an All-Electric Ship
}

This paper compares the approaches to power flow control and network stability of an integrated ship power system through reducing the dynamics of large loads to operate in compatibility with the dynamics of a traditional generating system, or through the methods of "smarter" generators through its power electronic interface.

By Marco Cupelli, Ferdinanda Ponci, Senior Member IEEe, Giorgio Sulligoi, Senior Member IEEE, Andrea Vicenzutti, Student Member IEEE, Chris S. Edrington, Senior Member IEEE, Touria El-Mezyani, Member IEEE, And Antonello Monti, Senior Member IEEE

ABSTRACT | The concept of an all-electric ship, while offering unprecedented advantages from the point of view of efficiency and flexibility of operation, has introduced new challenges in terms of stability and power flow control. The advent of a full power electronics power system has raised new questions from the point of view of system dynamics, particularly when dealing with the new medium-voltage direct current distribution. The overall goal of guaranteeing a secure operation of the power system has brought researchers to consider two main approaches: reducing the dynamics of the large load to operate in a range of dynamics compatible with traditional generation systems, or making the generator set smarter through its power electronics interface. This paper compares these approaches to stable operation, focusing on the latter considered more in line with the progress of technology and in general more appealing.

Manuscript received April 3, 2015; revised October 1, 2015 and October 23, 2015 accepted October 27, 2015. Date of current version November 18, 2015.

M. Cupelli, F. Ponci, and A. Monti are with the Institute for Automation of Complex Power Systems, RWTH Aachen University, Aachen 52062, Germany (e-mail: mcupelli@eonerc.rwth-aachen.de; fponci@eonerc.rwth-aachen.de;

amonti@eonerc.rwth-aachen.de).

G. Sulligoi and A. Vicenzutti are with the Department of Engineering and Architecture, University of Trieste, Trieste 34127, Italy (e-mail: gsulligoi@units.it; avicenzutti@units.it).

C. S. Edrington and T. El-Mezyani are with the Centre for Advanced Power Systems, Florida State University, Tallahassee, FL 32310 USA (e-mail: edrington@caps.fsu.edu; elmezyani@caps.fsu.edu).

Digital Object Identifier: 10.1109/JPROC.2015.2496789
KEYWORDS | Centralized control; control nonlinearities; decentralized control; load management; microgrids; power distribution; power system stability; stability analysis; stability criteria; system-level design

\section{INTRODUCTION}

Traditionally, the electrical power system did not play a big role in the design of ships. The first change occurred with the introduction of electrically propelled ships. A further major push originated from the introduction of the concept of the all-electric ship (AES) proposed by the U.S. Navy. The key technology that has really changed the design options is power electronics and, in particular, the idea of a power electronic building block [1], [2]. The $\mathrm{AES}$, at least as design concept, is one of the first real power-electronics-based power system that was ever considered. Similar development happened in the avionic field with the concept of more electric aircraft [3]. Power electronics enabled the possibility to actively control the flow of power in the system to an unprecedented level. Standardization activity has led to concepts of automation design that are completely hardware independent and able to operate effectively at system level [4]. In this respect, ship power systems as well as avionic systems anticipated terrestrial power systems proposing architectures based on a full control of the power flow [6]. A good example in this direction is given by the interest in direct current (dc) technology that is now making its way to terrestrial 
systems [5]. While power-electronics-based electrical power distribution has been investigated and applied in other industries, particularly aircraft industry, the AES is a full electric system, where power is distributed to propulsion motors as well as other large and small, critical and noncritical loads onboard. For this reason, the focus of research around the AES, which has produced the current concept, is on system, which is the main focus here.

Given this equivalence, the overall automation concept can be separated into two fundamental challenges:

1) power balance between generation and load and corresponding actions for power dispatch and load curtailment;

2) voltage stability and corresponding short term real-time corrections.

In the following, this paper, after summarizing the main architectures adopted for modern ship power systems, focuses on the two aforementioned challenges. Particular emphasis is placed on the second one reporting a complete overview of the current research trends for medium-voltage direct current (MVDC) ships. This paper does not aim to provide an ultimate solution addressing stability in modern ship power systems since factors like the ship intended operation and mission, its power system realization, and the requirements with respect to the operational secure region have to be taken into consideration [7], [8]. However, general recommendations are provided based on the consideration of different centralized and decentralized, load side, and generation side stabilization approaches.

\section{SUMMARY OF POSSIBLE SHIP ARCHITECTURES}

\section{A. Conventional Ships}

Until the start of the 20th century, ships were mechanically propelled. Steam engines/turbines were directly connected to the propellers, providing power required to move the ship. An evolution occurred around the middle of the century, when steam turbines/engines were substituted with diesel engines, but the system architecture remained unchanged. In this type of vessels, the electrical power system was simple and had a reduced extension. In fact, it was only used to power the lighting systems and the radio equipment. One or more diesel generators, which produced the electric power needed by the loads, and a low-voltage distribution system, normally constituted the electrical power system. In particular, distribution was in dc for low power application (where battery sources also can be used, especially in short range crafts) but more commonly in alternating current (ac). The complexity of the onboard electrical power system began to increase only when the power of the loads increased, and when more systems were connected to the electric power system.
Although this system architecture is outdated in general, it still survives in low power applications (such as small leisure crafts), or in applications with high navigation speed requirements (such as naval vessels or ferries), or even in applications in which the cargo can be used as fuel [such as in liquefied natural gas (LNG) and coal carriers].

An example of modern large power application of mechanical propulsion is shown in Fig. 1, where the power system of IT Navy Aircraft Carrier Cavour is depicted [21]. The electrical power system is based on a highly survivable ring architecture, endowed with eight separated generators, to supply the electric loads. Conversely, mechanical propulsion is achieved through four gas turbines (total power about $88 \mathrm{MW}$ ) coupled with two variable pitch propellers, to propel the ship up to about $28 \mathrm{kn}$.

\section{B. All-Electric Ships-AC Power System}

Since high power electronic converters for marine applications entered the market (about 30 years ago), they have been extensively adopted in the propulsion systems of ships, starting from the cruise sector. Their operation as variable speed drives allowed the substitution of mechanical combustion engines with electrical motors, leading to a revolution in the onboard power systems design. This marks the birth of the so-called all-electric ships (AESs). The complexity of electrical distribution onboard as well as power levels greatly increased. In fact, in AESs, the electric power system has to supply not only the propulsion system, but also common loads (such as pumps, HVAC systems, etc.), whose total power is comparable to that of propulsion, or even greater. Consider, for example, that the propulsion power of a cruise ships is about $25-40 \mathrm{MW}$. Following load power increase, the generation system power had to comparably increase, reaching $100 \mathrm{MW}$ (the record of $117 \mathrm{MW}$ of total installed power belongs to cruise liner Queen Mary 2).

The electric propulsion carries several advantages with respect to mechanical propulsion:

- better dynamic response;

- possibility to locate the internal combustion generators away from propulsion shafts, thus optimizing their position in the ship's hull;

- enhanced control of electric propulsion systems (acceleration and maneuvering);

- possibility to modulate the number of running diesel generators, so as to reach the maximum efficiency;

- lower vibrations, consequently augmented comfort;

- possibility of positioning the motor-propeller groups outboard, into rotating pods, thus eliminating rudders and improving maneuverability.

In an AESs, the integrated power system (IPS) makes the integration of electric propulsion and ship's electric loads possible [22]. In Fig. 2, an example of such a system, taken from a cruise ship, is shown.

For an AES, the IPS is the core as it supplies almost every subsystem onboard, such as air conditioning, hotel 


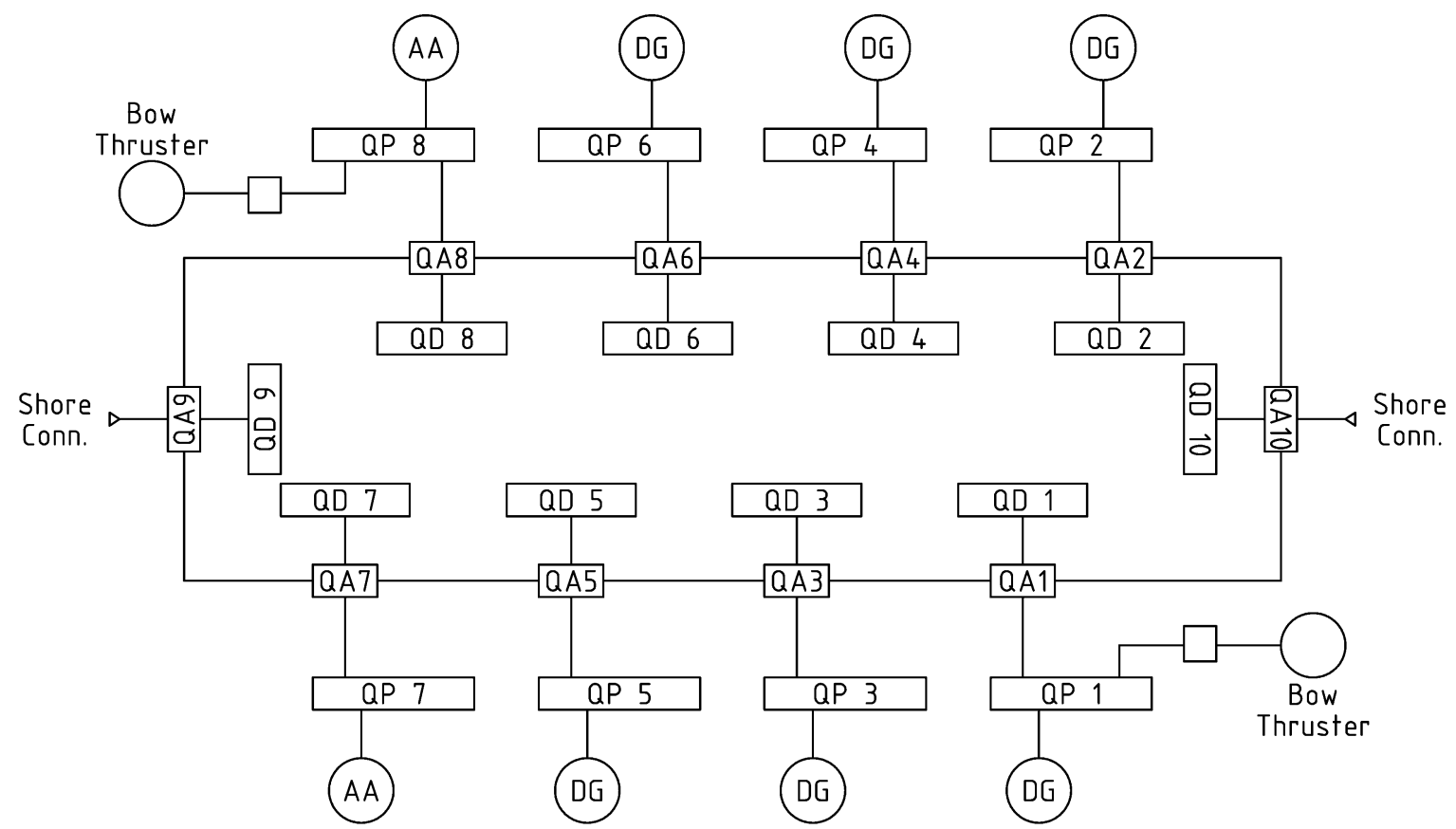

Fig. 1. IT Navy Aircraft Carrier Cavour electric power system.

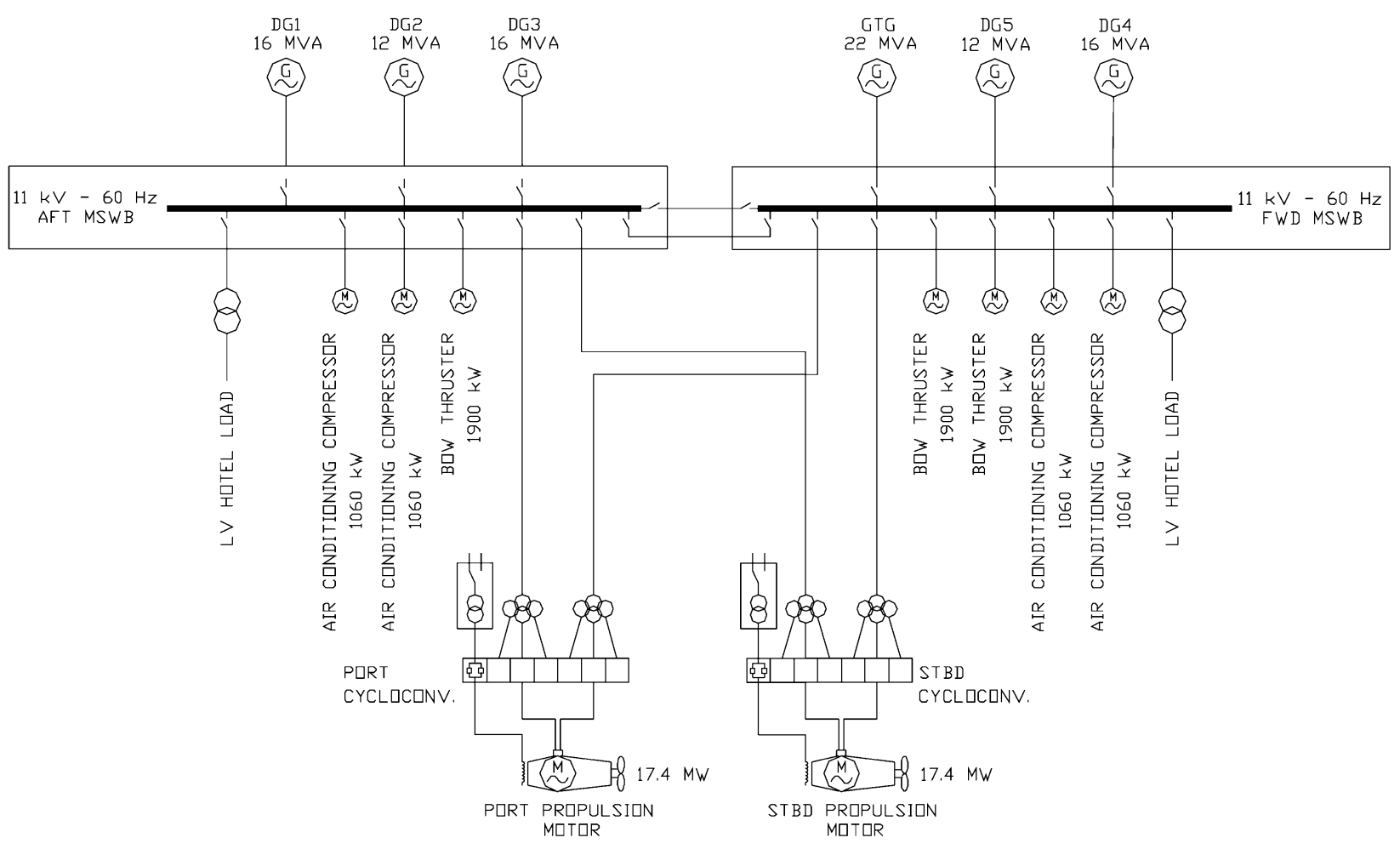

Fig. 2. Typical cruise all-electric ship power system. 
loads, and special loads, as could be found in military applications. During normal operation outside the harbor, the AES lacks connection to a larger ("stiff") electrical system that would stabilize voltage and frequency. Therefore, the IPS onboard must meet independently the demanding requirements of high power availability and power quality. Commonly, the IPS relies mainly on the control systems of the generators to meet these requirements. Hence, the coordination between generator control systems, ship automation, and protections is necessary, and must be taken into account in design to avoid critical issues in these islanded power systems [23].

\section{All-Electric Ships-DC Power System}

The adoption of electronic power conversion onboard allows a broad range of advantages according to [24]:

- limitation and management of fault currents, and possibility of ease of reconfiguration;

- enabling of bidirectional power flows;

- improved control of power flows, especially in transient and emergency conditions;

- improved efficiency, by adopting energy storage and power conversion from batteries or fuel cells.

Thanks to recent advancements in power electronics, a long lost architecture for onboard power systems can be brought back: the dc distribution [25], [31], [32].

Designing a ship power system adopting de distribution will permit the following additional advantages:

- simplified connection and disconnection of different types and sizes of power generators and storage devices;

- reduction of size and ratings of switchgears;

- elimination of large low-frequency transformers;

- elimination of reactive voltage droop;

- reduction of fuel consumption by allowing variable speed prime movers operation;

- elimination of the phase angle synchronization of multiple sources and loads.

Due to the high power levels required in modern AESs, the only viable design option for distribution is the adoption of voltage higher than $1 \mathrm{kV}$, leading to the MVDC distribution proposal. An MVDC distribution system integrates several groups of power sources and loads, all connected to the main dc bus through electronic power converters, which regulate the load voltage supply. Fig. 3 shows an example of such system, depicting a notional radial MVDC power system, hosting four generators and several loads. Commonly ships have four to six generators, which have to be interfaced with the MVDC bus with high power converters. Conversely, in ships, the number of loads is very high, thus requiring a relevant number of converters to supply them. Loads can be grouped in load centers, but commonly high power loads are supplied singularly, while low power loads are grouped in load zones. Nevertheless, the majority of these converters have much smaller power than generator converters, as only few are high power loads (mainly propulsion, thrusters, and HVAC compressors). For this reason, the number of high power converters onboard is limited, and these are concentrated at the interfaces between high power systems (generators and relevant loads) and the MVDC bus.

The loads can be either supplied in medium voltage, for high power loads, or through low-voltage secondary distribution sections, for low power loads. The ratio of high power loads to generation side converters and the associated load dynamics are highly dependent from the selected ship type - military or civilian (cruise, cargo) and load type (propulsion, pulsed power). The MVDC distribution looks promising for both merchant ships (mainly cruise ships, but also ferries, tankers, etc.) and naval (i.e., military) vessels. For this reason, the development of this technology advances regardless of the area of application, but the differences between merchant and military vessels are reflected in the development. In a nutshell, the main differences between the power systems of these two groups of ships are mainly on the level of redundancy, fault tolerance, loading pattern and survivability required in military systems [26], which also has to accommodate more pulsed loads and in which the total load demand may in principle even surpass the available generation, where approaches like redundancy and reconfiguration are seen as critical to increase survivability [27].

\section{POWER BALANCING AND RECONFIGURATION}

The first critical challenge for the modern ship power system is the dispatch for power balancing combined with restoration and reconfiguration. These challenges are very similar to those of the high level control of a microgrid in islanded mode, where the total demand may be larger than the total generation. This condition holds true in ships for normal and abnormal operating conditions.

A ship may undertake various missions and operate for a broad range of activities requiring specific power generation and distribution patterns [28], [29]. Research work has addressed this in [7], which includes the possibility to divide the operating conditions of the IPS into several operating states, to identify the level of system security. Four operating states are defined for the IPS: normal state, alert state, emergency state, and restorative state. Based on the state of different control actions to stabilize the bus, new operation set points or load shedding are carried out by the platform management system (PMS) [30]. These actions are then implemented in the framework of a security constrained power management system, which enables the selection of the best suited combination of control schemes.

The power balancing problem in an IPS can be mapped on to the tertiary control of the classic terrestrial grid, and can be implemented in centralized form, or in a decentralized fashion, e.g., via multi-agent system 


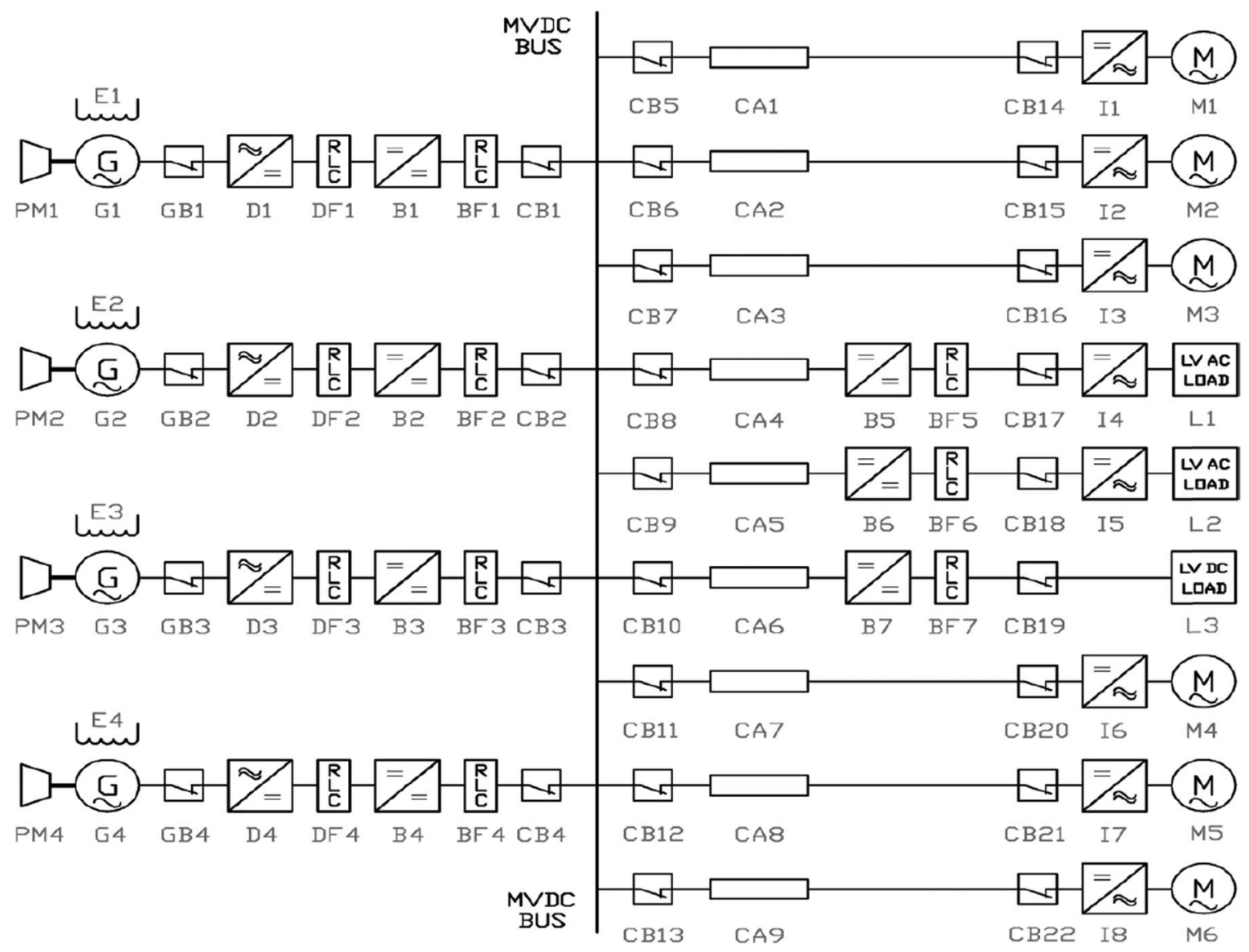

Fig. 3. Notional MVDC power system.

framework. In fact, the vast majority of implementation proposals for distributed and decentralized control and protection of power electronics-based power systems onboard future electric ships are based on multiagent systems [9], [10]. Since the beginning of the IPS, the presence of power electronic converters allowed the consideration of advanced demand side management (DSM) options mostly based on load prioritization logics. The load shedding and prioritization mentioned here refer to schemas where load shedding is implemented as continuous performance degradation, and load prioritization is dynamic, with priorities based not only on the needs and criticality of the loads but also on their impact on the electrical system [4], [11]-[13]. In a broader sense, the introduction of power electronics reopened another important theoretical discussion: centralized versus distributed automation approach [9].

The value of the distributed solution is particularly appealing from the point of view of survivability: agentbased control reduces the danger of single point of failure. The capability of agent systems to reconfigure themselves depending on the operating conditions allows continuing operation also under extreme conditions. On the other hand, centralized solutions typically benefit from the availability of global information that can be better exploited for optimization purposes.

A complete overview of the application of agent technology can be found in [14]. A focus on the specifics for ship power systems is given in [15]. Agent-based solutions have been actually proposed for different critical tasks for the high level automation such as:

- $\quad$ ship power system restoration and reconfiguration [16], [17];

- $\quad$ power quality [18];

- $\quad$ PEBB high level interface [15].

While to the best of our knowledge, these technologies have not been adopted so far, other than at experimental level, in vessels currently in service, they are becoming more and more appealing and close to real life application in terrestrial applications [19], [20].

However, for what concerns real ship power systems, the adopted solutions are still based on very traditional, centralized power dispatching.

\section{STABILITY}

Let us now focus on the second main challenge identified for the automation of modern ship power systems: 
stability. This section introduces the term stability in electrical systems to better clarify the context of the challenge discussed here. Stability issues can be classified into three families and correspond to the behavior of the following variables [33]:

- the rotor angle of synchronous machines;

- the frequency of ac networks;

- the bus voltage (ac or dc).

The first family concerns the mechanical speed of rotation of synchronous machines, which is directly proportional to the electrical frequency of the stator. The magnetic field of the rotor, generated by the excitation windings, has to remain aligned with the magnetic field of the stator; otherwise, the machine loses the synchronism and becomes unstable. When a synchronous generator is coupled to a power system with fixed frequency, it must maintain the rotation speed needed to remain aligned with the network reference, although its relative position may vary in a certain range. The difference between the position of the axis of the rotor and of the network field is called the rotor angle, and stability can be evaluated with respect to two different conditions: steady state and transient. "Steady-state angle stability" concerns the stability of the rotor angle following small disturbances, thus referring to the stability of the electrical machine working point. Conversely, "transient angle stability" concerns the stability of the system after large perturbations (such as short circuits), thus being connected to the dynamic evolution of the system variables [36].

The second family is related to the frequency of power systems, which is strictly related to the balance between power demand and generation in the system. If the power demand increases, while the generated power output does not follow this variation, then system frequency decreases. Vice versa, if load decreases so the generated power output is larger, the frequency will increase. The frequency deviation from nominal can therefore be regarded as an indicator of the variation of the power balance in the network [34]. The maximum frequency deviation, i.e., unbalance, that a system can sustain is limited, so regulation has to be adopted to maintain the balance between absorbed and generated power constantly. The frequency stability regards the stability of such a control system, and the stability of the complex interactions between these and the entire power system. Our focus here is on dc distribution systems on ships, therefore the frequency stability is not addressed any further.

The last family of stability challenges relates to the stability of bus voltages. Bus voltages are stabilized after a transient around an equilibrium point. Kundur et al. say that "Voltage stability refers to the ability of a power system to maintain steady voltages at all buses in the system after being subjected to a disturbance from a given initial operating condition. It depends on the ability to maintain/restore equilibrium between load demand and load supply from the power system. Instability that may result occurs in the form of a progressive fall or rise of voltages of some buses" [33, p. 1390]. The voltage stability can be classified based on the magnitude and the duration of the disturbance (large/small, long/short).

Given this definition, the stability of an electric system can be defined as its ability to recover its initial operating point, or another one in a certain range from the initial one, after a disturbance which has shifted the operating point of the system away from the initial one. To complete this definition, it is also important to state the mathematical criteria for stability. These allow characterizing the different natures of stability, especially when continuous and discontinuous systems are considered.

\section{A. Mathematical Definition of Stability}

$$
\begin{cases}\dot{x}=f(t, x), & x \in D \\ \forall t>0, & f(t, 0)=0 .\end{cases}
$$

If system (1) is defined and differentiable in $R^{n}$, and $D$ contains the origin, from a mathematical point of view, the equilibrium point $x=0$ of (1) is:

- stable, if for all $\varepsilon>0$ and $\delta\left(\varepsilon\left(t_{0}\right)\right)>0$, the following holds:

$$
\left\|x\left(t_{0}\right)\right\|<\delta \Rightarrow\|x(t)\|<\varepsilon \quad \forall t \geq t_{0} \geq 0
$$

- uniformly stable, if for any $\varepsilon>0, \delta=\delta(\varepsilon)>0$ exists, independent of $t_{0}$ and such that (2) is fulfilled;

- asymptotically stable, if it is stable and $\eta\left(t_{0}\right)>0$ exists such that

$$
\left\|x\left(t_{0}\right)\right\|<\eta\left(t_{0}\right) \Rightarrow \lim _{t \rightarrow \infty} x(t)=0
$$

- unstable in all other cases.

Equation (2) states that if the system has an initial state $D$, then a circle of radius $\varepsilon$ from $D$ can be found, in which the system evolves over time without ever leaving this circle.

Conversely, (3) requires the system to eventually reach the point of equilibrium; no deviations around it are allowed. Thus, this definition is stricter than simple stability. For these definitions of the equilibrium point to be applicable, it is necessary that the relevant signals for stability assessment be represented by terms that are constant in steady state [37]. Such a description can be achieved with averaging modeling techniques, for balanced ac systems with reference frame theory [38] and multiple reference frame theory [39] for unbalanced ones. Consequently, the voltage of an ac grid will not be asymptotically stable, even though it may be stable in the sense of (2). For 
power electronics the situation is more difficult as the switching prevents the system from reaching a true equilibrium point [37]. For example, the measured output current of a buck converter is stable in the sense of bounded-input-bounded-output (BIBO) but it is not asymptotically stable because of the switching operation. On the other hand, from an averaged modeling perspective, asymptotic stability is also possible for power converters.

Both the averaged and switching models are presented in this paper.

\section{B. Angle Stability in Islanded Systems}

The angle stability of a synchronous generator is the ability to maintain the synchronism between the rotor field and the network variables during both static and transient conditions. In this paper, we refer only to small disturbances, like the ones that occur in power systems in normal operation, thus referring to the so-called "steady-state stability." Conversely, large perturbations (transient stability) are beyond the scope of this paper.

The aperiodic angle stability is related to the presence of at least one positive real pole in the system's characteristic equation. This kind of instability was a potential issue in the past, because voltage control loops were very slow (time constants of seconds). Because of that, the active powerfrequency loop was well separated from the reactive powervoltage loop, so power disturbances affected the system in a frequency band where the excitation was nearly constant. Therefore, the only instability issue possible in the electromechanical loop of the system (including generators, network, and loads) was the aperiodic one, caused by an insufficient synchronizing power coefficient [35].

The synchronizing power coefficient indicates the stiffness of the electromagnetic coupling between rotor and stator in a synchronous electrical machine, and is defined as follows:

$$
k=\left(\frac{\partial P_{e}}{\partial \delta}\right)^{0}
$$

where $P_{\mathrm{e}}$ is the electric power generated by the synchronous generator, $\delta$ is the electrical angular position of the rotor with respect to the reference frame rotating at nominal speed, and superscript 0 indicates that coefficient $k$ has to be calculated at the equilibrium point.

The well-known necessary condition for the rotor angle $\delta$ to have a stable operating point in a synchronous generator is

$$
-\frac{\pi}{2}<\delta<\frac{\pi}{2}
$$

The synchronizing power coefficient $k$ must be positive to have a stable operating point. However, its value is also relevant. In fact, if $k$ is large, the coupling is stiff and vice versa. A too stiff coupling will cause issues, due to the excessive mechanical stress at the rotor of the machine after a sudden load change. Conversely, too loose coupling will cause issues due to the possible loss of synchronism after a load disturbance. The coupling stiffness depends on both the internal reactance of the machine and the portion of system reactance interposed between the machine and the reference point (namely external reactance). The larger is the reactance, the lesser is the coupling. This feature is well known, and it has less impact on shipboard power systems. In fact, being the external reactance very low in onboard installations (due to the limited spatial extension and the direct connection of synchronous generators to the switchboards), the coupling is very high. Because of this, the synchronizing power coefficient in shipboard power systems is large, avoiding the risk of aperiodic instability.

For what concerns oscillatory angle stability, it corresponds to at least one pair of complex conjugate poles, with a positive real part in the characteristic equation of the system. In synchronous machines, this issue commonly arises if two or more generators are connected to a common coupling bus, or if a synchronous machine is connected to a fixed reference point (in voltage amplitude and frequency). In these cases, the rotors of synchronous machines move around their steady-state equilibrium point in response to small disturbances in the system. These oscillations are called "electromechanical oscillations." If the electromechanical oscillations are damped, the machine's rotor angle returns to its original equilibrium point, otherwise it will oscillate with increasing amplitude up to the intervention of the protections (tuned to protect the machine). Even in presence of damping, issues can arise; oscillating transients after a disturbance may be unacceptably long. Methods to assess system's damping and eventually increase it are well known and commonly adopted almost wherever needed. This issue has not been a problem in the past, when the slow voltage regulators were used. In fact, the damping given by the dissipative elements of the system, particularly the damping cage, embedded in synchronous machine rotor especially for this purpose. Conversely, the use of very fast modern voltage regulators, whose operation creates a coupling between electromechanical and voltage loops, usually worsens the damping of electromechanical oscillations, leading in some cases to unstable conditions or inadequate performance [35].

This topic has been extensively addressed in case of grid connected generators, and it is well understood, as demonstrated in literature, for example, [36] and [40][42]. In fact, the "standard analysis approach" is the Heffron-Phillips model [36], [40]. Conversely, publications regarding the case of generators in islanded operation (disconnected from the grid) are scarce. This may be due to the very low penetration of islanded operating 
generators, a situation that is changing due to, e.g., the interest in microgrids.

When referring to islanded systems, electromechanical stability has to be carefully addressed. In fact, in such systems, the electromechanical stability depends first on the structure of system. If a single synchronous generator supplies a linear system, then there is no need for electromechanical oscillation damping. This is due to the lack of a fixed reference with respect to which the generator's rotor must synchronize, since the single generator itself imposes the system variables. Conversely, the stability challenge may arise in presence of two or more synchronous generators connected to the same bus. In this case, the rotor fields of the machines can relatively slide during transients. Another case in which the electromechanical transient stability issue may be present is the case of a generator supplying a load through a static power converter. In fact, the converter may behave like a generator on the ac side, depending on its control system. This could be either a desired effect, like in virtual inertia stabilizing actions, or a side effect of the control law embedded in the converter. Then, the load converter may interact with the generator, causing electromechanical instability.

In the following, a possible approach to address electromechanical transient stability (in particular the issue of the electromechanical oscillations damping) in islanded power systems is presented and demonstrated for a typical, simplified shipboard power system layout.

To provide an intuitive understanding of the electromechanical transient stability, the simplified islanded system depicted in Fig. 4 is adopted as case study. The system is symmetrical and fed by two identical generators (the same parameters and control systems).

Through the analysis of the system in state-space domain and its linearization around a given operating point, it is possible to decompose the system into two separated electric subsystems. In fact, in the case here depicted, the main bus bar can be assumed as the system's point of symmetry. This means that the bus bar can be considered as the coupling point for the two generators, leading to two different models depending on the disturbances of the

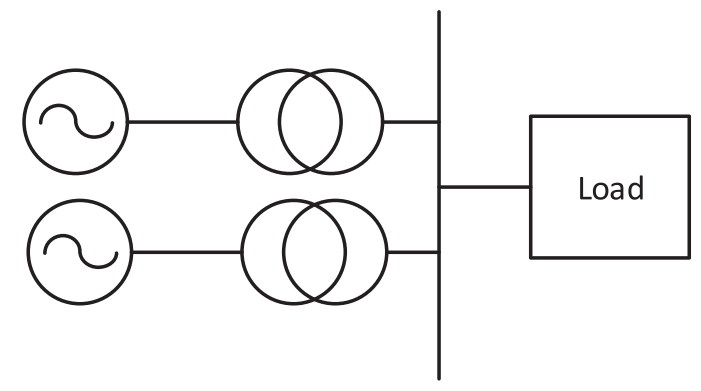

Fig. 4. Two generators islanded power system.

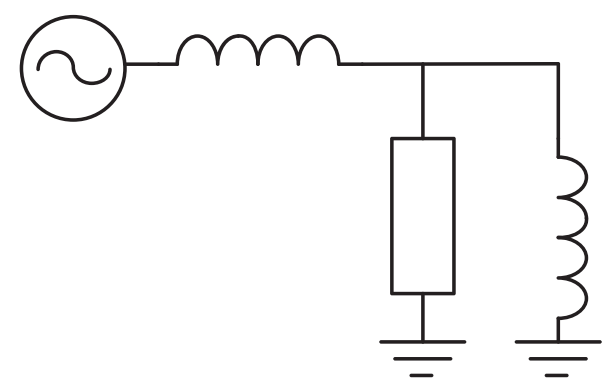

Fig. 5. single generator connected to a load.

internal states of the generator (symmetrically or antisymmetrically variations). In fact, if the internal states of both generators move jointly (symmetrically) after a disturbance, the two can be considered as a single generator, and the bus bar voltage would move accordingly. Conversely, if the internal states of the two generators move in opposition (antisymmetrically), the bus bar voltage can be considered as fixed, because the variations induced by the two generators cancel each other out.

By decomposing a complex disturbance into a sum of symmetrical and antisymmetrical variations of the internal state, it is possible to separately analyze the effect of such disturbance on the system. This can be easily done by applying the decomposed disturbances to the appropriate decomposed subsystem. The decomposition of the system yields two subsystems, with the same state-space equations, but different state variables: one subsystem for the symmetrical components, the other for the antisymmetrical components. The transients of symmetrical variables can be studied through a single generator connected to a load model, as depicted in Fig. 5, while antisymmetrical components can be studied with a single generator connected to a constant voltage point model, as depicted in Fig. 6.

In the system in Fig. 5 there are no electromechanical stability issues, because the decomposed subsystem behaves like a single generator system feeding a linear load. Conversely, in the system in Fig. 6, electromechanical stability issues may appear, because the resulting subsystem behaves like a single generator connected to an infinite power bus. In this case, the standard techniques for electromechanical stability assessment can be applied, e.g., as proposed in [36].

In particular, the system of Fig. 6 can be represented with the well-known Phillips-Heffron model [36], [40],

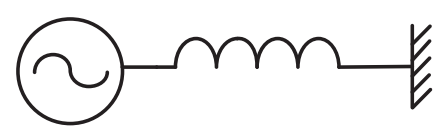

Fig. 6. Single generator connected to a constant voltage point. 


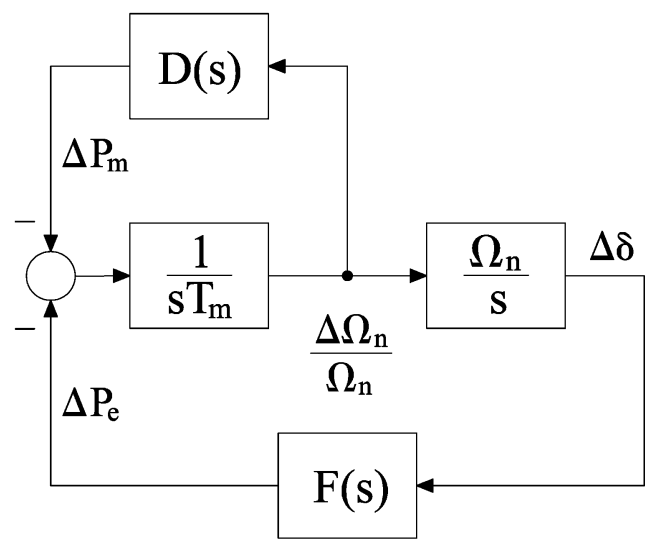

Fig. 7. Phillips-Heffron model of a grid connected synchronous generator.

depicted in Fig. 7, where $D(s)$ is composed of frequency regulator and prime mover actuators, and $F(s)$ models the effect of the entire voltage control loop on the electromechanical loop. This model links the power unbalance of the generator (the difference between mechanical input power and electrical output power) with its phase shift $\Delta \delta$, which is the difference between the internal rotor angle and the network reference angle. Thanks to this model, the stability assessment for the antisymmetrical subsystem is possible, and so eventually the electromechanical transient stability of the complete system.

A more detailed explanation of the decomposition technique can be found in [43], where also the dynamic interactions between voltage and frequency control in this kind of systems are assessed. In fact, it is known that voltage control can affect electromechanical stability of a synchronous machine [36], but normally the control bandwidth of voltage and frequency controls are well separated by design. Conversely, in islanded systems, frequency controls must have a large bandwidth to assure the frequency regulation performance required to compensate for the lack of grid connection. In this case, voltage and frequency controls can interact to worsen electromechanical stability. Improvement in damping can be achieved like in terrestrial systems, by injecting stabilizing signals in the voltage regulation cycle [power system stabilizer (PSS)] [41], [42].

\section{Voltage Stability in AC Power Systems}

Conventional linear loads pose little threat to voltage stability of the system. However, in some cases, they can lead to unexpected problems, such as bad coordination between alternators' voltage controls and busbar voltage control [44], or between reactive power capability controls of paralleled alternators (causing reactive power oscillations between them) [23]. Conversely, with new nonlinear devices, such as power electronic converters, new unprecedented issues emerge. The presence of power converters causes the challenge of constant power load (CPL) voltage instability. Indeed, when a power converter is regulated with high bandwidth, it tends to keep its absorbed power constant, in spite of the variations of voltage of the feeding bus. This nonlinear behavior causes the increase of the current drained by the converter as bus voltage drops. This behavior, opposite to that of conventional loads, challenges voltage bus stability.

The primary cause of this issue is the high control bandwidth of the converters, which, however, is also the main design feature of this kind of systems. In fact, one of the main advantages of applying electronic power conversion is the decoupling of the electric variables of the loads from those of the power supply, enabling control of the load regardless of what happens upstream. But the higher the required performance is, the higher is the necessary control bandwidth, thus worsening the CPL instability problem. It is not possible to quantify univocally the minimum bandwidth that destabilizes the system, because it depends both on the system itself and on the operating point [51]. To assess the worst case scenario, the commonly applied hypothesis is to assume ideal CPLs, i.e., converters capable to control their output variables with infinite bandwidth.

To study the impact of CPL on an ac system, the singlephase simplified system of Fig. 8 is adopted here.

In this system, the source and the network (including cables, transformers, etc.) are modeled as a constant voltage source with a series RLC branch, while loads are grouped in two equivalents, one linear and one CPL loads, both with unity power factor. The choice to limit power factor to unity limits the state variables to be taken into account, but has a relevant impact on stability assessment. In fact, nonunity power factor would increase the count of system state variables by one for each equivalent load, thus complicating the analysis. Moreover, these additional components would worsen the stability of the system, so ignoring them may lead to misleading results. However, the proposed approximation can be considered acceptable for this first assessment [45].

To assess the voltage stability, a small signal model can be adopted, evaluating the variations of system variables in the neighborhood of a given operating point (namely $V_{0}$ ).

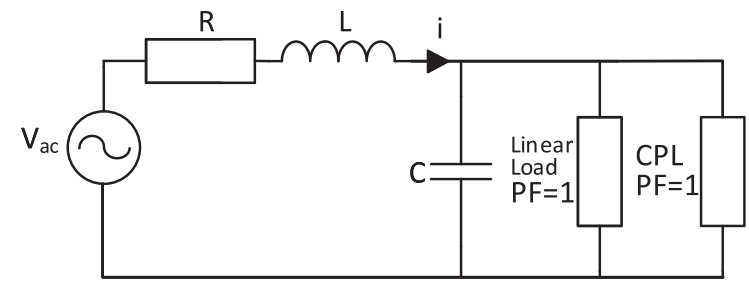

Fig. 8. Simplified ac system for the analysis CPL instability. 
Linearizing the nonlinear system of Fig. 8, the CPL load can be modeled with the negative resistance $R_{C P L}$

$$
R_{\mathrm{CPL}}=\frac{V_{0}^{2}}{P_{0}}
$$

where $R_{C P L}$ is the CPL loads equivalent resistance module; $V_{0}$ is the Busbar voltage at the operating point; and $P_{0}$ is the total power of CPL loads.

Linear loads, conversely, can be represented with a fixed resistance value $R_{\text {lin }}$ and their total power $P_{\text {lin }}$. Analyzing the system, the small signal linearized system in the frequency domain yields the following transfer function:

$$
\frac{V_{0}}{V_{\mathrm{ac}}}=\frac{\frac{1}{L C}}{s^{2}+\left[\frac{L+\frac{R C R_{\operatorname{lin}} R_{\mathrm{CPL}}}{R_{\mathrm{CPL}}-R_{\operatorname{lin}}}}{L C C_{\operatorname{lin}}^{R_{\mathrm{CPL}}}}\right] s+\left[\frac{R+\frac{R_{\operatorname{lin}} R_{\mathrm{CPL}}}{R_{\mathrm{CPL}}-R_{\operatorname{lin}}}}{L C \frac{R_{\operatorname{lin}} R_{\mathrm{CPL}}}{R_{\mathrm{CPL}}{ }^{-R} \operatorname{lin}}}\right]} .
$$

The real part of the poles of this transfer function indicates the stability of the system. Applying the RouthHurwitz criterion, it is also possible to determine the following two necessary and sufficient conditions for small signal stability:

$$
\begin{aligned}
& R_{\mathrm{CPL}}>\left(R \| R_{\text {lin }}\right) \\
& P_{\mathrm{CPL}}<P_{\text {lin }}+\frac{R C}{L} V_{0}^{2} .
\end{aligned}
$$

AES power systems are limited in overall dimension, so cable lengths are reduced in comparison to terrestrial systems. The series resistances of the elements between generators and loads ( $R$ in Fig. 8) are usually very small in shipboard power systems, due to the reduced extension of the system (maximum cable length commonly $<200 \mathrm{~m}$; some exceptions up to $350 \mathrm{~m}$ ). This leads to the satisfaction of (8) in almost every case. Therefore, (9) is the most restrictive condition, leading to a careful consideration of how much CPLs a system can withstand before instability arises.

An extensive description of the voltage stability analysis in ac systems can be found in [46], where a more accurate analysis is also carried out, using DQ-transformation and taking into account the interaction between $d$ - and $q$-axis. A stability analysis approach for early stages of system design is proposed, together with considerations on both the system's parameter $(R, L, C)$ influence on stability and the possible methods to improve it. Some case studies are presented in [46], with different stability behavior depending on the operating point. Finally, a simple though

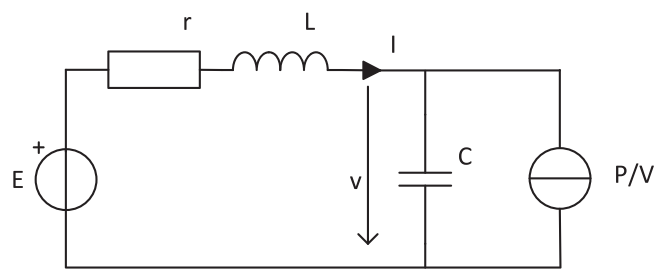

Fig. 9. Electrical system containing a nonlinear load.

rough classification of loads that can be regarded as CPL is presented in [46], to help using the assessment procedure.

\section{Introduction to Constant Power Load Connected to a DC Bus}

In an MVDC AES, the electrical subsystems are connected to a dc bus. Those subsystems will be interfaced with power converters. The interaction between the power converters and the dc bus is associated with the instability caused through CPLs [47], [48], [50].

CPL behavior appears when there is an element which regulates (e.g., inverter/actuator, converter/battery converter, drive) power consumption of the load. The control of the load side converter will then compensate for disturbances. The load side converter does not use information about the electrical state of the network (including the dc bus). The dc bus sees it as a constant power consuming element, as shown in Fig. 9 [88]. The output of the source converter is represented by the voltage source $E$, which is interfaced through a filter circuit consisting of the equivalent series resistor of the inductor $(r)$, inductor $(L)$, and capacitor $(C)$ with the nonlinear load, which is represented by a current source with the characteristic $P / V$, where $v$ denotes the voltage drop over the capacitor.

The current was absorbed by CPL from the dc bus being equal to $I_{\mathrm{CPL}}=P / V$, thus the introduction of a CPL in the network implies the appearance of a nonlinearity of the $P / V$ type. The characteristic current/voltage across the $\mathrm{CPL}$ is represented in Fig. 10. In order to observe the behavior of the CPL around a given operating point $\left(I_{0}, V_{0}\right)$, it is possible to linearize through the tangent at the operating point. This linear characteristic, given by the equation of the tangent, takes the form of

$$
i_{\mathrm{CPL}}(t)=\frac{P}{V_{0}^{2}} V(t)+2 \frac{P}{V_{0}}
$$

and it comprises a first term dependent on $R_{\mathrm{CPL}}$, the negative resistance defined by

$$
R_{\mathrm{CPL}}=-\frac{V_{0}^{2}}{P}
$$




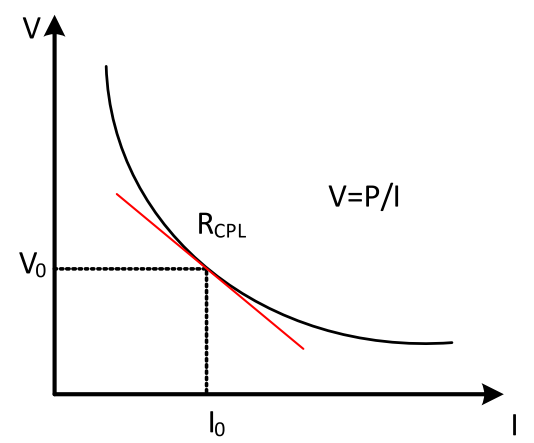

Fig. 10. Characteristic I/V curve of a CPL.

and a second term, which is a dc component. So, the CPL behaves like a negative resistance around each operating point. Fig. 11 shows graphically the electrical behavior of the CPL around a given operating point.

The mathematical representation of the effect of the CPL and $R_{\mathrm{CPL}}$ on the network can be written in statespace form

$$
\left[\begin{array}{c}
\dot{V}(t) \\
\dot{I}(t)
\end{array}\right]=\left[\begin{array}{cc}
\frac{-1}{C R_{\mathrm{CP}}} & \frac{1}{C} \\
\frac{-1}{L} & \frac{-r}{L}
\end{array}\right]\left[\begin{array}{c}
V(t) \\
I(t)
\end{array}\right]
$$

Focusing on the variations around the operating point, thus omitting the dc component of (10), leads to the polynomial model in

$$
P(\lambda)=\lambda^{2}+\left(\frac{r}{L}+\frac{1}{C R_{\mathrm{CPL}}}\right) \lambda+\frac{1}{\mathrm{LC}}\left(1+\frac{r}{R_{\mathrm{CPL}}}\right)
$$

Enforcing poles with negative real part in this polynomial characteristic yields the relationship in

$$
\left\{\begin{array}{l}
R_{\mathrm{CPL}}<-r \\
R_{\mathrm{CPL}}<-\frac{L}{r C}
\end{array}\right.
$$

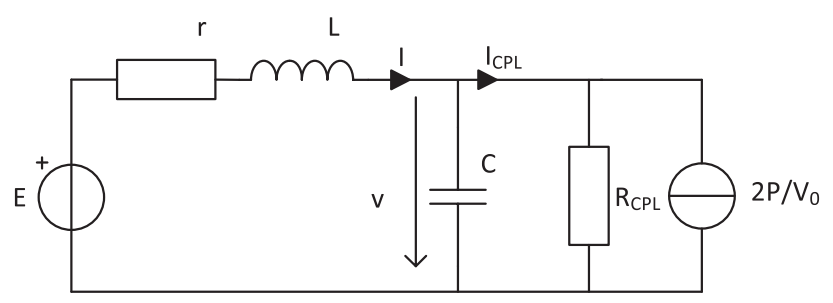

Fig. 11. Electrical system containing a CPL, an equivalent circuit around the operating point. which states the stability criteria. The first inequality always holds because of the negative sign of $R_{\mathrm{CPL}}$ and usually the equivalent series resistor $r$ is very small when comparing the absolute values, while the second may not always hold since an increase in load power causes an increase in current, which leads to an increase of $R_{\mathrm{CPL}}$, which then tends to 0 .

By replacing this second inequality for $R_{\mathrm{CPL}}$ in the expression of power yields

$$
P<\min \left(\frac{r C}{L} V_{0}^{2} ; \frac{V_{0}^{2}}{r}\right)
$$

for example, the local stability condition for the system. The relation $P<V_{0}^{2} r^{-1}$ is less restrictive than the relation $P<0.25 V_{0}^{2} r^{-1}$, which ensures the existence of a stable operating point for the system, while relation in

$$
P<\frac{r C}{L} V_{0}^{2}
$$

gives the stability condition for possible operating points of the system.

Equation (16) shows the relationship between the stability of the system and the sizing of the filter $(r, L, C$, and indirectly $E$ ) and the power consumed by the load. The larger the value of the capacitance, the more stable the system is, and vice versa for the inductance of the filter. In addition, these observations show that the negative resistance excites the system because it "generates" reverse current changes, triggered by voltage changes. So, the more power the load absorbs, the more its equivalent conductivity increases until it compromises the overall damping of the system, after which the system becomes unstable.

The two possible assumptions regarding the CPLlinearization around operating points or full nonlinear characteristic - lead to two groups of method for stability assessment.

\section{E. Study Methods for the Stability of a Linear System}

This section summarizes the methods and mathematical tools to study the stability of linear systems. All these methods are based more or less directly on the poles of the system.

A similar approach lies in the study of the poles of the system transfer function, as they express its behavior (response time, damping) and its asymptotic stability. The system is stable if the poles of its transfer function have a strict negative real part. These methods nevertheless require modeling of the system in a form of state or transfer function which can in some cases happen to be restrictive.

The system depicted in Fig. 11 can also be represented by a cascade of two subsystems. The study of their 


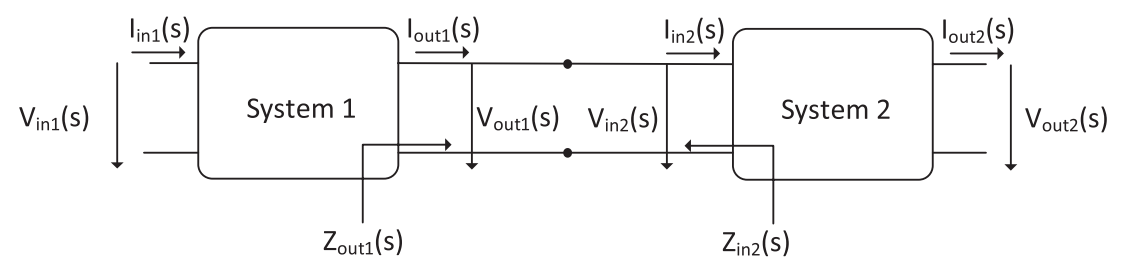

Fig. 12. Two-port impedance model.

interaction relies on the decomposition of the complete system into electrical subsystems and their respective impedances in the frequency domain [51].

The stability of the cascaded system depends on the interaction between the input and output impedances of subsystems, as depicted in Fig. 12, where "System 1" represents the source and "System 2" represents the load.

This approach also enables evaluating the stability margins. The criteria are based on the Middlebrook restriction of the gain of the ratio $Z_{\text {out } 1} / Z_{\text {in2 }}$. This condition forces the Nyquist plot to be smaller than 1 . Fig. 13 gives a graphic representation of the Middlebrook criterion for two systems connected in cascade, where the Nyquist plot is required to stay inside $1 / \mathrm{MG}$, where $\mathrm{MG}$ represents the gain margin of the closed-loop system. This can be transformed into a design condition for the input impedance of "System 2," when the output impedance of "System 1" is given.

To summarize, the system will be stable if the following inequality holds:

$$
\left|\frac{Z_{\text {out1 }}(s)}{Z_{\text {in2 }}(s)}\right|<\frac{1}{\mathrm{MG}}, \quad \mathrm{MG}>1
$$

The method of gain margin (MG) and phase margin (MP) is another stability criterion, which can also be used during the design phase of closed-loop control in cascaded systems, based on a principle similar to Middlebrook's,

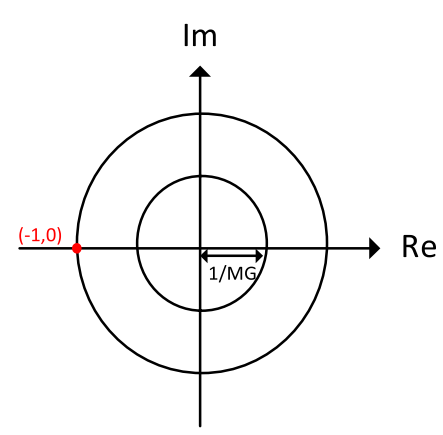

Fig. 13. Middlebrook criterion. however it tends to be less conservative. The method of Middlebrook limits the $Z_{\text {out1 }} / Z_{\text {in2 }}$ gain across the frequency domain. To have a less conservative stability criterion, an MG-MP criterion has been developed by defining a forbidden region to ensure the system has enough MG and MP. The definition of forbidden region is the gray area in Fig. 14. A comprehensive overview of stability criteria in dc systems can be found in [52] and [53].

\section{F. Study Methods for Nonlinear Systems}

The methods for assessing the stability of linear systems presented in the previous section are also applicable to nonlinear systems that can be linearized around their operating point. In this case, we talk about the "small-signal" stability. The model and assessment are valid only for small changes around the operating point.

These methods tell whether a system is stable at one operating point. This knowledge can be enhanced by determining security margins, which quantify the range, around the operating point, within which the system remains stable. However, it cannot be assured that the system can switch from one stable operating point to another while remaining in a stable condition.

To address this aspect it is necessary to use nonlinear tools that define the basins of attraction and lead to "largesignal" study of stability. The approaches surveyed here are based on the seed work of Lyapunov, who proposed a theory to the study of the stability of nonlinear systems. 
This theory is based on the search and the existence of socalled Lyapunov characteristic functions. Subsequently, these Lyapunov functions are used to obtain the system of attraction basins. Examples of such approach applied to dc distribution systems can be found in [54]-[57].

\section{STABILIZING CPLS}

In onboard MVDC systems, shipboard loads are either directly connected through power converters to the MVDC bus or grouped into load zone interfaced to the MVDC bus through power converters. A key control design goal for interface converters is voltage stability, which may be jeopardized by the presence of CPLs, which are high bandwidth controlled loads.

The following literature review shows control solutions for the CPL problem.

As discussed in previous sections, the interactions on the dc bus between the electrical systems may be unstable. In order to protect the system against this risk of instability, several solutions are possible. The "passive" solution consists in sizing the passive component, i.e., filter, to ensure the stability. Different input filter structures may also be used to maximize the impact on the stability of the system [58]. Nevertheless, the use of the passive solution increases the size (weight, mass) of the system, which may be very penalizing for some applications such as aeronautics or naval systems.

Particularly for these systems, the implementation of stabilizing controls is more convenient. These control solutions can be of different types, depending on whether the dc bus is regulated.

\section{A. Stabilizing From the Load Side}

In order to increase the stability of the system without changing its structure or increasing its size and weight, it is possible to implement a stabilizing state feedback on each individual load side converters interfacing the loads toward the dc bus, while not altering the behavior of generators and the converters which supply the dc bus.

The destabilizing impact of the CPL depends on the converter control imposing a load power, irrelevant of the magnitude of voltage provided by the network.

The idea is to design a stabilizing load control by including the necessary information about the state of the bus voltage to the control function. This information can be used to generate a signal $(\Psi)$, which when added to the reference power, will increase the stability of the system. The principle of this type of control is summarized in Fig. 15 and relies on the same principle: emulate a virtual impedance by control. This approach was discussed in [59]-[62].

This principle presents, as the main advantage, a clear and intuitive meaning. In order to improve the stability of the system, it is sufficient to increase the size of the "virtual capacity" or the "virtual resistance." The "virtual

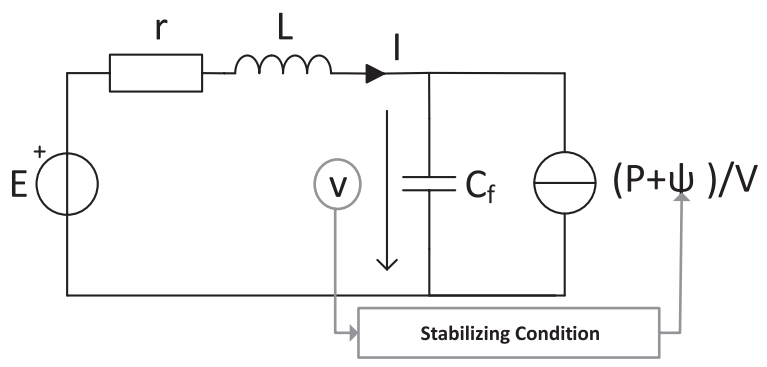

Fig. 15. Load side stabilizing control.

resistance" addition is usually defined as active damping [50], as its intervention increases system damping as real resistance would, but implementing it via the converter control system. It is a nonlinear method. In fact, it consists in adding an additional signal to the reference voltage input of the converter, which lowers the reference as the output current increases. To avoid the voltage drop in a steady state condition, the "virtual resistance" signal is filtered, as to intervene only during transient conditions. This method can be simply implemented at the load side, as the load converter measures its own output current and voltage for control and protection purposes, and the additional signal depends only on the local load supplied.

Other methods available in the literature may present the implementation of a linear correction as has been done in [61] and [63]. In these cases, the impact of the stabilizing action on the stability of the new system is assessed by studying the influence of the control on the input impedance of the load. Another approach was presented in [59], where an exact input/output linearization of the original nonlinear system was proposed. The authors claim that the advantage of this method is to offer a stabilizer whose size is independent of the operating point, thus ensuring the large signal stability of the system and not only around an operating point.

\section{B. Load Side Stabilization Using Real-Time Load Shedding}

Shedding electrical loads during inadequate generation or voltage swing is vital to assure stable operation of electric power systems [64], [65]. The load shedding process is used as a backup solution when the system experiences unbalance between loads and generations. Ship's limited resources require consideration of the load shedding measure at all times (i.e., in normal operating conditions and emergency situation). In conventional load shedding methods, frequency settings, time-delay settings, and the amount of load to be shed in each step are set to constant values [66], [67], which is not the most efficient scheme for all power system disturbances. In order to consider a wider range of perturbations, a real-time adaptive load shedding scheme (LSS) has been proposed 
to improve the operation of the conventional LSS and enhance power system stability [68], [69]. The load shedding requirement is calculated based on the computed disturbance power as well as the voltage stability condition, using real-time data [70], [71]. The decision to shed loads and the number and position of loads to shed is determined based on the power imbalance estimation. The active power imbalance $\Delta P_{G_{i}}$ at the ith generator can be estimated as

$$
\Delta P_{G_{i}}=\left[P_{m i}-P_{s i}\right]-\frac{2 H_{i} S_{i}}{f_{n}} \frac{d f_{G i}}{d t}
$$

where $H_{i}$ is the inertia of the ith generator; $S_{i}$ is the rated apparent power (MVA) of the ith generator; $f_{n}$ is the rated system frequency ( $50 \mathrm{~Hz}$ in this paper); $f_{G i}$ is the frequency of the ith generator; $P_{m i}$ is the mechanical power of the ith generator; and $P_{e i}$ is the electrical power of the ith generator.

The amount of active power load to be shed at the $j$ th load bus, denoted as, is given as

$$
\Delta P_{L_{j}}=\frac{\Delta V_{L_{j}}}{\sum_{j=1}^{M} \Delta V_{L_{j}}} \Delta P
$$

where $\Delta V_{L_{j}}$ is the voltage deviation at the $j$ th load bus compared to the rated frequency (e.g., $50 \mathrm{~Hz}$ ); $P_{L_{0 . j}}$ is the amount of active power load at the $j$ th bus before disturbance; and $M$ is the total number of load buses. More detail about the load shedding decision can be found in [71] and [72].

Although most of real-time load shedding techniques guarantee a fast response to the system instability, they do not consider the loads based on their priority, which is instead required in the shipboard power system (SPS). In fact, in SPS, several loads cannot be shed as they are vital to the mission of the ship. Table 1 shows a general framework for defining the load priorities for an SPS. Propulsion typically has the highest priority, while

Table 1 Load Priority Assignement Example for a Naval System [73]

\begin{tabular}{|l|l|l|l|l|}
\hline $\begin{array}{l}\text { Load } \\
\text { Alert }\end{array}$ & Domestic & Lifeboats & Propulsion & Weapons \\
\hline In Port & High & Low & Low & Low \\
\hline Patrol & Medium & Medium & High & Medium \\
\hline $\begin{array}{l}\text { General } \\
\text { Quarters }\end{array}$ & Low & Low & High & High \\
\hline $\begin{array}{l}\text { Abandon } \\
\text { Ship }\end{array}$ & Low & High & Low & High \\
\hline
\end{tabular}

domestic loads such as lighting in crew quarters and galley power are less vital to the ship [73].

Traditionally, in the SPS, loads have been classified in three predefined groups of nonvital, semivital, and vital loads. The importance of a load change depends on operating conditions and the ship mission(s).

In fact, depending on the operating condition of the ship, the load may be vital in one mission and semi-vital or vital in another.

The load shedding problem has been formulated in [74] and [75] by updating the priority for each load and developing the AHP load prioritization module (ALPM) and the expert control actions determination module(ECADM). The ALPM uses the analytical hierarchy process (AHP) to prioritize the loads. Load prioritization occurs at each runtime by assigning a weight factor to each load. The weight factor is obtained by combining the significance level and the critical natures of loads.

The weight factors associated with different priority status of loads are assigned by AHP, which generates the priority lists of all loads in the system in different situations. Then, for a given amount of load to be shed, loads with lower priorities are shed first until LSS satisfies the shedding requirement. The block diagram of the load shedding scheme is shown in Fig. 16. The dynamic database is constantly updated with current SPS state. ALPM also takes as inputs the present mission(s) from a dynamic database. A ship at any given time may be executing one or a combination of missions. Taking these inputs, the ALPM uses AHP to order the loads in SPS in an increasing order of priority and passes this list to the ECADM. ECADM searches the dynamic database to obtain the system state information, consisting of various static, connectivity and real-time data, such as the status of the circuit breaker, bus transfer, and relays. It also takes as input the amount of load to be shed. Using these inputs and based on a set of rules, the ECADM identifies loads to shed and determines the lowest number of control actions that will shed these loads. Finally, it enables the list of control actions to be executed and loads to be shed.

A detailed review of AHP and ECADM can be found in [76]-[78]. Multilogic Exsys Developer [79], used to develop the ECADM, identifies the loads with lowest priorities that should be shed and also determines the optimal control actions to shed such loads.

The AHP, ALPM, and ECADM modules are tested in simulation, in a real-time digital simulator (RTDS), on a ten-load dc zone of a notional destroyer-class SPS under the event of a battle scenario. In this scenario, it is assumed that the ship is attacked while cruising (mission 1). An overload of $109.1 \mathrm{~kW}$ is detected, while the ship is operating in "Mission 1." A detailed description of the scenario and simulation model of the notional destroyerclass SPS is available in [74] and [80].

ALPM requires formation of two judgment matrices to calculate weight factors for load prioritization. Judgment 


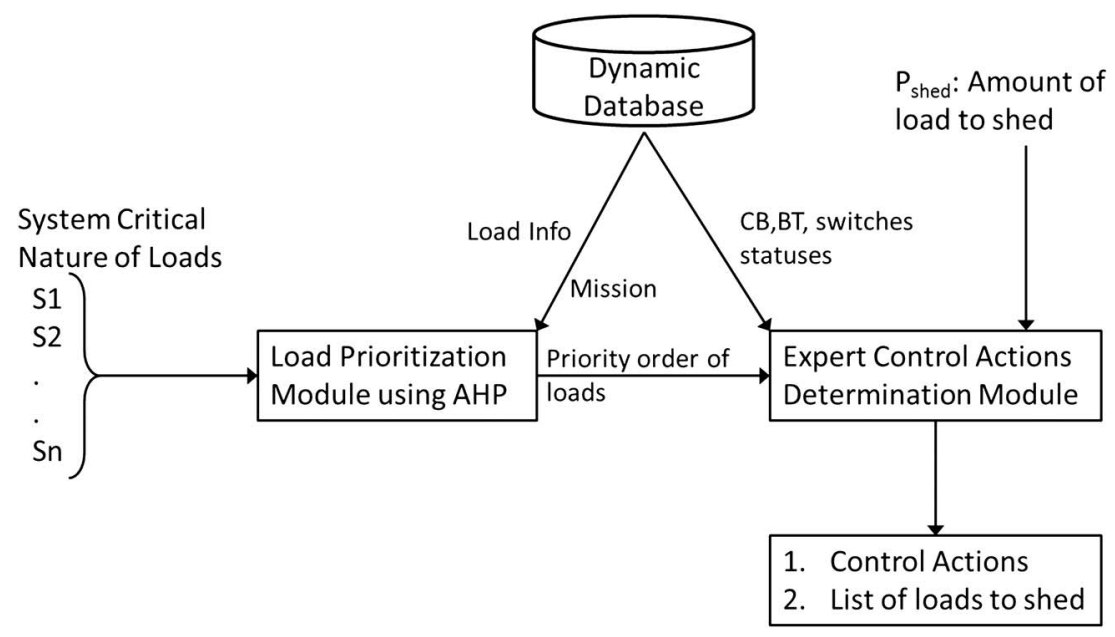

Fig. 16. Block diagram of the load shedding scheme [78].

matrices of different significance levels and system critical natures of loads can be formulated by analyzing the survey results from experienced system operators.

Fig. 17 shows the simulation results of the evolution of dc over time, in "Mission 1," for the system before and after the load shedding. I2OUTP is the current of the dc bus that powers the dc loads. In such an overload situation, the remaining online generator(s) may get overloaded in an attempt to supply electrical energy to the loads of the ship. Thus, load shedding actions are required to shed some load(s) so that the online loads can get continuous electrical supply, increasing the ship's survivability chances.

Fig. 18 shows the evolution of dc over time, before and after the load shedding in Mission 2. More details about the scenarios in Mission 1 and Mission 2 can be found in [78].

\section{Stabilizing From the Generation Side}

A stiff dc bus is crucial in applications that feature a heavy penetration of pulsed loads, such as military ships. The pulsed load magnitude can be two to three orders

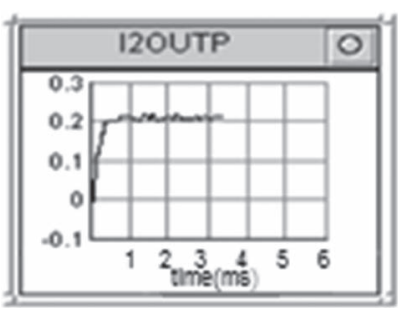

(a)

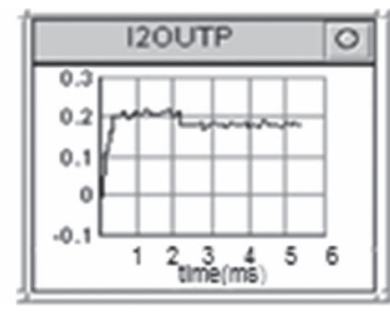

(b)
Fig. 17. "Mission 1" overload of 109.1 kW: (a) before load shedding; and (b) after load shedding; loads 1, 6, and 7 shed in response to an overload of $109.1 \mathrm{~kW}$ [78]. larger than the total power installed [81], and their usage may cause the system voltage to sag momentarily; as a consequence, this could trip sensitive control loads offline [82]. In such conditions, generation side control approaches guarantee the dc bus stability.

When the control of the $\mathrm{dc} / \mathrm{dc}$ converter, which feeds the CPL depicted in Fig. 19, is accessible, the so-called generation side control or, alternatively, the bus voltage control is possible. In this case, the system to be stabilized possesses a new control variable: the duty cycle $(d)$ of the $\mathrm{dc} / \mathrm{dc}$ converter. It should be pointed out that the voltage source $E$ represents rectified voltage. It is then possible to integrate the constraints related to the stability of the system in the control of this converter. The idea of this method has been introduced the first time several years ago while considering the "small-signal" stability of the system [83], [84], but also the "large-signal" stability has been incorporated [85].

More recently, this work has been supplemented by new control approaches dealing with "large-signal"

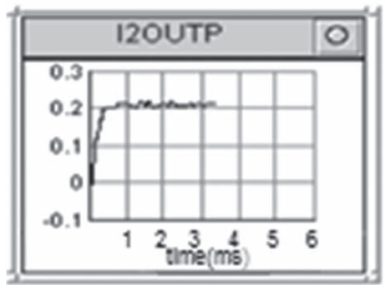

(a)

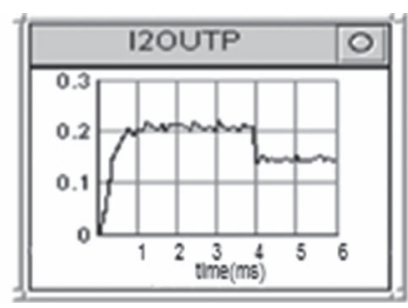

(b)
Fig. 18. "Mission 2" overload of 156.9 kW: (a) before the load shedding; and (b) after load shedding in response to the overload in Mission 2 [78]. 


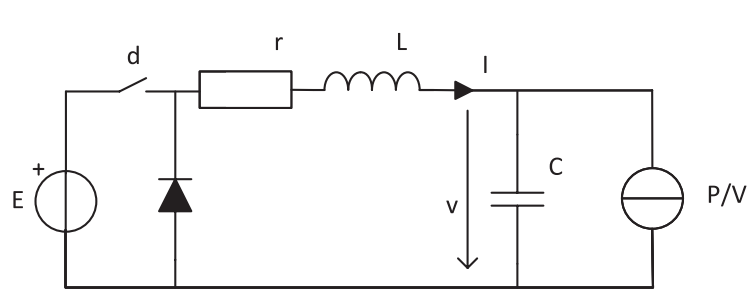

Fig. 19. Constant power load fed by a dc/dc converter.

stability of these systems [49], [50], [86]-[92], [107]. These proposed nonlinear controls incorporate the stability of the system in the design of the control laws. For example, Kwasinski and Krein [87] rely on the passivity properties of the system, while Rivetta et al. [88] and Zhao and Qiao [90] use sliding mode control to increase the stability of the system.

Onwuchekwa and Kwasinski [91], [92] apply boundary controllers, which implement a state-dependent switching, the opposite of sliding mode control, which instead applies a time-dependent switching.

In [93]-[95], [107], the authors propose the implementation of synergetic control laws. This nonlinear law has similarities with the sliding mode control but offers one additional parameter, which defines the speed of convergence toward the manifold. Another main difference compared with the sliding mode control is that the synergetic control law operates with fixed switching frequency to stabilize CPL systems.

Rahimi and Emadi [50] and Rahimi et al. [89] propose the implementation of a gain that directly compensates for the nonlinear term in the CPL and therefore cancels out the source of instability. This technique is called linearization via state feedback (LSF), and consists in injecting through the converters a signal on their output voltage, which is capable of compensating for the nonlinear part of the system. To enable the implementation of this method, converters must have enough regulation bandwidth to effectively apply the signal, so the LSF can be successfully applied only to converters with high switching frequency, such as the dc/dc ones of Fig. 3. Using other types of converters to interface generators with the MVDC bus, such as diode or thyristor rectifiers, the LSF cannot be applied on the bus controlling converters but must be relegated to the load side for CPL compensation [96].

In [97], the usage of parasitic effects for stabilization was presented while the modified pulse adjustment technique was presented in [98]. The advantage of these approaches is that they do not need to change the reference of the CPL to ensure the stability of the system.

When applying a dc bus voltage stabilization scheme, the output of the source converters is regulated in such a way that the voltage is kept stable without changing the behavior of the individual CPL.
In [99] and [100], a decentralized control approach was presented which decouples multiple parallel generation side converters from each other. Each generation side converter operates only with a local model and without knowledge of the rest of the power system. This concept uses a Kalman filter for state estimation in combination with a setpoint trajectory to adjust the system deviations, which arise from applying a linear optimal control law. This concept was successfully implemented in a hardwarein-the-loop (HiL) setup in [99] and [100]. The decoupling mechanism of the Kalman filter can also be applied to a backstepping controller, which is a nonlinear controller that uses Lyapunov functions to guarantee stability. A comparison between a combination of a backstepping control with Kalman filter versus an adaptive power estimation technique in combination with backstepping control is shown in [100] and [102].

\section{Active Damping in Multimachine systems}

Active damping ( $\mathrm{AD}$ ) is easy to implement in single converter applications, such as load side control, but becomes challenging in generator side control, due to the presence of more than one converter paralleled on the same bus. In [104], an application of AD to the ship's multimachine MVDC power system of Fig. 3 has been presented. Fast controlled dc/dc converters interface generators to the MVDC bus, and can be used to apply the $\mathrm{AD}$ to stabilize the system. To correctly apply the $\mathrm{AD}$, an evaluation of system's damping has to be done, so as to define how much damping needs to be added through the "virtual resistance." Considering a single generator system, its buck converter and filtering stage can be represented as in Fig. 20.

A small-signal linearized analysis made in the neighborhood of an equilibrium point yields the following characteristic equation:

$$
s^{2}+\frac{1}{L C}\left(C R-\frac{L}{R^{0}}\right) s+\frac{1}{L C}\left(1-\frac{R}{R^{0}}\right)=0
$$

where $R_{0}=V_{0}^{2} / P$ is the magnitude of the negative incremental resistance of the linearized CPL.

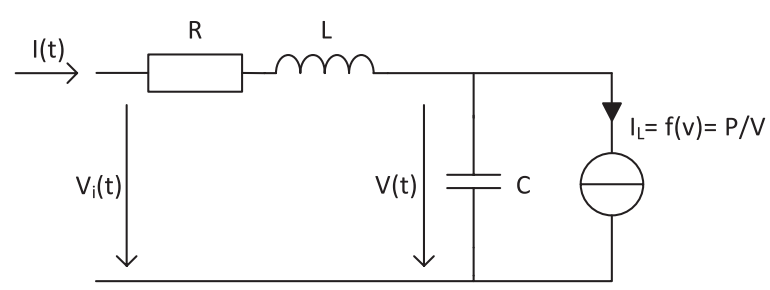

Fig. 20. Buck converter output and the filtering stage. 


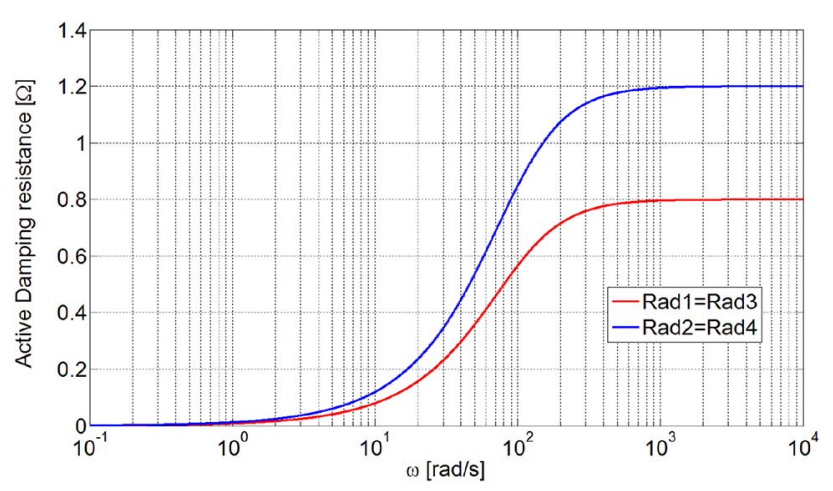

Fig. 21. Active damping resistances for two converter power sizes.

Considering the worst case, in which a pure CPL absorbs the total system load power with negligible system series resistance, the following natural angular frequency and damping factor can be calculated for the single converter:

$$
\begin{aligned}
\omega_{0 f} & =\sqrt{\frac{1}{L C}\left(1-\frac{R}{R_{0}}\right)} \\
\hat{\xi}_{f} & =-\frac{1}{2 R^{0}} \sqrt{\frac{L}{C}}
\end{aligned}
$$

These expressions can be easily adapted to the evaluation of a multimachine system damping by adjusting the load level, considering the total capacitance in the system, and evaluating the equivalent inductance given by the parallel of all the buck converters of the generating system. The possibility to simplify the multimachine system with a second-order model has been discussed in [103].
To calculate the virtual resistance value $\left(R_{\mathrm{ad}}\right)$ to be added to the system in order to ensure the proper damping effect, the following equation can be used:

$$
\xi_{t}=\frac{1}{2 \omega_{0 f} L} R_{\mathrm{ad}}+\xi_{f}
$$

where $\xi_{t}$ is the target damping for the system.

The virtual resistance thus calculated has to be added to the converters through proper control modification, so as to realize an equal partition of the damping action among them. In particular, this can be achieved imposing the same per unit value of resistance for each converter, therefore realizing a sharing of the damping action proportional to individual power. To avoid the steady state voltage drop, the $\mathrm{AD}$ additional signal can be filtered with a first-order high-pass filter as in Fig. 21, to assure intervention only during transients. An example of AD implementation in a system is shown in Figs. 22 and 23. The left-hand side of Fig. 22 shows a centralized regulator for a multimachine MVDC system. It is composed of three blocks that assure system stability [the power signal stabilizing (PSS) block], equal load sharing between generators/converters (the power sharing block), and bus voltage regulation. The PSS block is composed of single stabilizing blocks, each acting on one converter, which implements the filtered AD, as shown in Figs. 23 and 24. Simulation results presented here validate the effectiveness of this centralized regulator. Fig. 24 shows the comparison of bus voltage transients: one case is in presence of full $\mathrm{AD}$ control, the other with loss of $\mathrm{AD}$ control from one of the converters. The partial loss of AD control causes the loss of system damping, conversely demonstrating the effective damping of $\mathrm{AD}$.
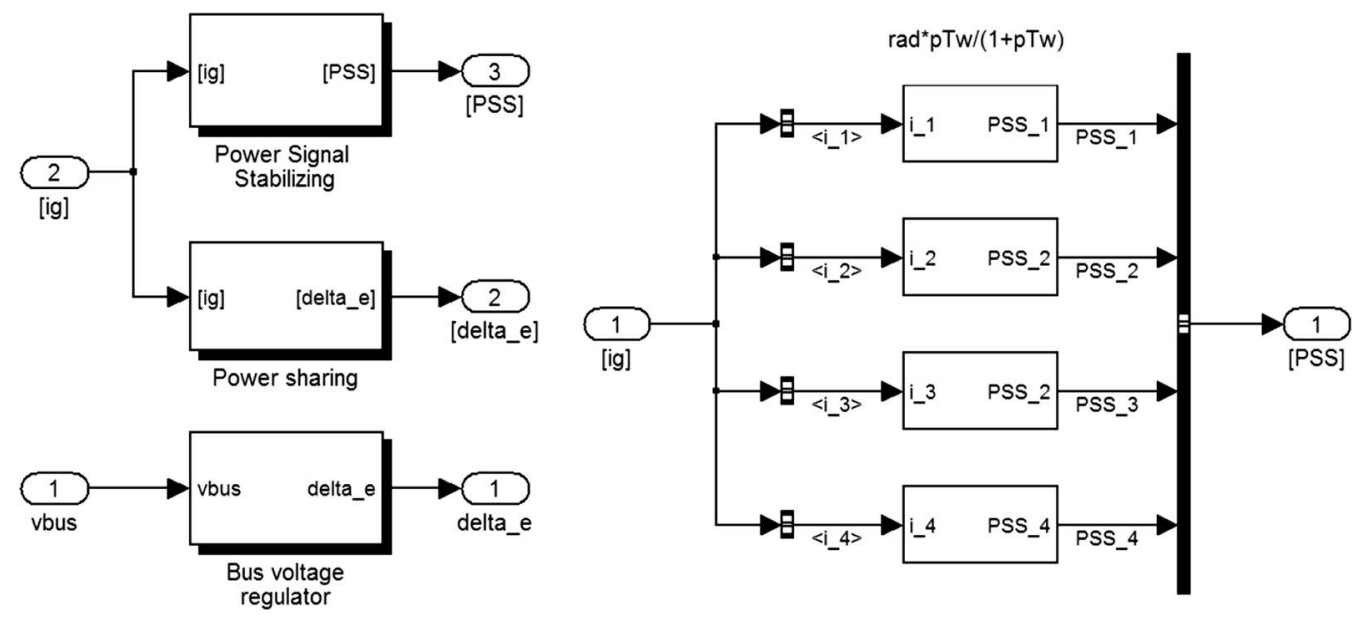

Fig. 22. System centralized regulator (left) and PSS control block (right). 


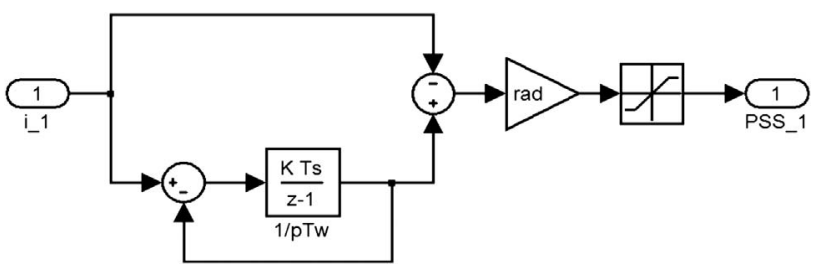

Fig. 23. Filtered active damping virtual resistance in a PSS control block.

The AD stabilizing method can be adapted to various system and loads configurations, recalculating $R_{0}$ to take into account variations in CPL load level, and recalculating $R_{\text {adwhen }}$ system equivalent inductance and capacitance vary, following generators connection or disconnection.

Despite all these positive features, the AD stabilizing method cannot stabilize systems with a high rate of CPL loads with respect to linear ones, because the system remains nonlinear. The damping intervention can act effectively on small disturbances, as it is based on small signal analysis, but fails when it comes to large disturbances. In this case, a more complex stabilizing method, capable of intervening also in large signal domain, such as the stabilization via state feedback, has to be adopted.

\section{E. Linearization via State Feedback in Multiconverter Systems}

Linearization via state feedback stabilizes the system by compensating for the effect of the CPL nonlinearity on the bus through a suitable signal injected by the converters. The calculation of the linearization signal is the critical point of this technique, as it needs a relevant measuring and calculation effort. Moreover, the implementation in a multiconverter system, such as the one in Fig. 3, requires the coordinated control of all the converters, to permit an effective sharing of the linearization signal and an effective stabilization of the system.

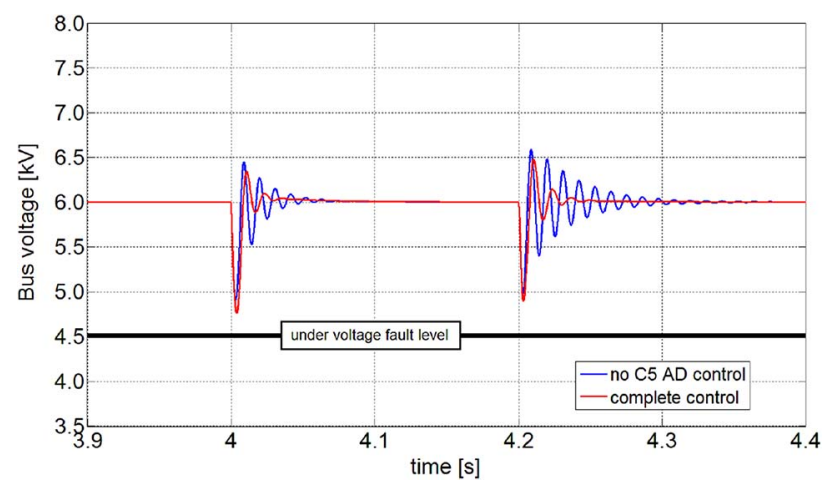

Fig. 24. Bus voltage transients: partial loss of AD stabilizing effect.

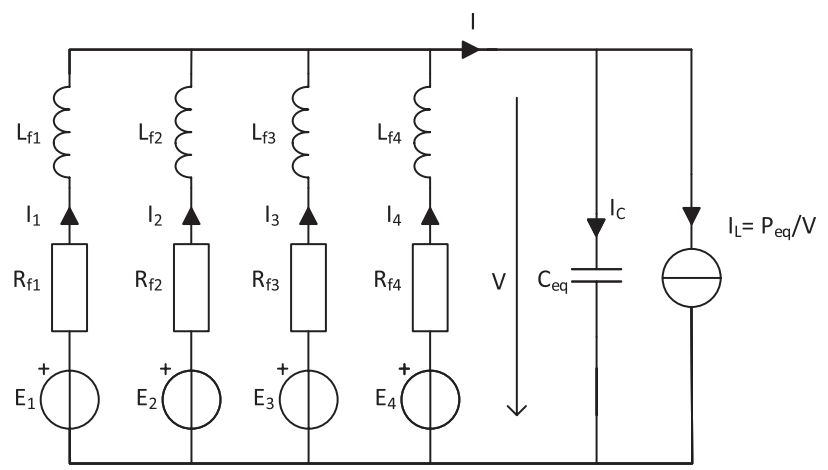

Fig. 25. Simplified circuit model of multiconverter MVDC power system.

A multiconverter system presents multiple state variables, as every converter has an output RLC filter. For example, the four-generator-nine-load system of Fig. 3 requires 23 nonlinear equations to be mathematically formulated (with some simplifications on the load side). The calculation of a suitable linearizing function with so many state variables is significantly complex, so some simplifying hypotheses have to be adopted. In [86], [103], and [106], it was presented that, if longitudinal parameters $(R, L)$ of the cables can be neglected with respect to the other system parameters (which is reasonable, given the limited spatial extension of shipboard power systems), all capacitors and loads can be considered parallel connected, and so an equivalent capacitance $C_{\mathrm{eq}}$ and an equivalent load (modeled with a current generator: $I_{L}=P_{\text {eq }} / V$ ) can be determined. Thanks to this simplification, the system can be represented with the reduced-order model of Fig. 25, and can be described by the following nonlinear state-space equations:

$$
\left\{\begin{array}{l}
\frac{d V}{d t}=\frac{1}{C_{\mathrm{eq}}}\left(I_{1}+I_{2}+I_{3}+I_{4}\right)-\frac{P_{\mathrm{eq}}}{C_{\mathrm{eq}} V} \\
\frac{d I_{k}}{d t}=-\frac{R_{f k}}{L_{f k}}-\frac{1}{L_{f k}} V+\frac{E_{k}}{L_{f k}} \quad \forall k=1,2,3,4 .
\end{array}\right.
$$

This system model can be further simplified if a suitable design for the filter consisting of RLC in Fig. 25 is adopted. In fact, ignoring the capacitive element, each filter can be designed in such a way so as to present the same time constant

$$
T_{f}=\frac{L_{f k}}{R_{f k}} \quad \forall k=1,2,3,4 .
$$

Doing so, the multiconverter system model is reduced to a second-order nonlinear model, described by the 
following equation:

$$
\begin{aligned}
\frac{d^{2} V}{d t^{2}}= & -\left(\frac{1}{T_{f}}\right) \frac{d V}{d t}-\left(\frac{1}{C_{\mathrm{eq}} L_{\mathrm{eq}}}\right) V \\
& +\frac{E_{1}}{C_{\mathrm{eq}} L_{f 1}}+\frac{E_{2}}{C_{\mathrm{eq}} L_{f 2}}+\frac{E_{3}}{C_{\mathrm{eq}} L_{f 3}} \\
& +\frac{E_{4}}{C_{\mathrm{eq}} L_{f 4}}-\frac{P_{\mathrm{eq}}}{C_{\mathrm{eq}} T_{f} V}+\frac{P_{\mathrm{eq}}}{C_{\mathrm{eq}} V^{2}} \frac{d V}{d t}
\end{aligned}
$$

where $L_{\text {eq }}$ is the parallel of the four filter inductances $L_{f k}$.

The last two addends of the equation represent the system's nonlinear components. The following shows suitable functions to cancel nonlinear behavior $\left(f_{l}\right)$ and to realize linearized system poles placement $\left(f_{c}\right)$ :

$$
\left\{\begin{array}{l}
f_{l}=-\frac{P_{\mathrm{eq}}}{C_{\mathrm{eq}} T_{f} V}+\frac{P_{\mathrm{eq}}}{C_{\mathrm{eq}} V^{2}} \frac{d V}{d t}=-\frac{I_{L}}{C_{\mathrm{eq}} T_{f}}+\frac{I_{L}}{C_{\mathrm{eq}} V} \frac{I-I_{L}}{C_{\mathrm{eq}}} \\
f_{c}=K_{1}\left(V-V_{0}\right)+K_{2} \frac{d V}{d t}=K_{1}\left(V-V_{0}\right)+K_{2} \frac{I-I_{L}}{C_{\mathrm{eq}}}
\end{array}\right.
$$

where $V_{0}$ is the steady state bus reference value, and $K_{1}$ and $K_{2}$ are gains, making it possible to realize the analytical pole placement.

The application of the combined control and linearizing functions to the multiconverter system requires splitting the LSF signal over the four generators, which can be done taking into account the load sharing set for each of them

$$
F_{k}=S_{k}\left(f_{l}+f_{c}\right) C_{\mathrm{eq}} L_{\mathrm{eq}}
$$

where $S_{k}$ are the load sharing coefficients for each generator $\left(\sum S_{k}=1\right)$.

The linear system resulting from the application of these functions on the second-order simplified one is represented by

$$
\begin{aligned}
\frac{d^{2} V}{d t^{2}} & +\left(\frac{1}{T_{f}}\right) \frac{d V}{d t}+\left(\frac{1}{C_{\mathrm{eq}} L_{\mathrm{eq}}}\right) V \\
= & \frac{E_{1}}{C_{\mathrm{eq}} L_{f 1}}+\frac{E_{2}}{C_{\mathrm{eq}} L_{f 2}}+\frac{E_{3}}{C_{\mathrm{eq}} L_{f 3}}+\frac{E_{4}}{C_{\mathrm{eq}} L_{f 4}}-K_{2} \frac{d V}{d t} \\
& -K_{1}\left(V-V_{0}\right) .
\end{aligned}
$$

Results shown in Figs. 26 and 27, where the same multiconverter system is simulated with and without the linearizing component of the proposed LSF function,

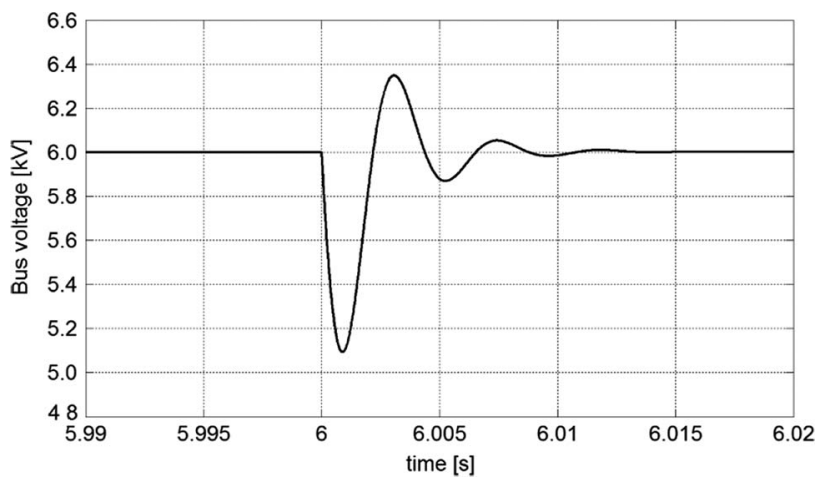

Fig. 26. Bus voltage transient ( $f_{I}$ on, $f_{c}$ on).

demonstrate the effectiveness of the LSF technique. After a sudden disconnection of one of the generating systems, the bus voltage, which was stable with active linearization function depicted in Fig. 26, becomes unstable if the linearization is removed, as shown in Fig. 27.

The LSF is much more effective than a small signal linearization, because it is not limited by the small signal hypothesis. Once the nonlinearity is canceled, all types of control functions can be adopted, in place of the proposed $f_{c}$, and can be easily evaluated as the system becomes linear.

This approach has been extensively described in [105] and [106] where the mathematical procedure was fully explained. Cupelli et al. [107] compare the LSF with synergetic control, discuss the system design and sensitivity analysis, and validate the LSF technique through both numerical and HiL simulations. In [106], a successful HiL implementation of the LSF was presented with the emphasis on the implementation and validation of the control in real hardware. The scope is to demonstrate that the LSF control can be implemented on field-programmable gate array (FPGA) and that the loss of numerical precision does not impact the stabilizing control. Cupelli et al. assess the impact of two different

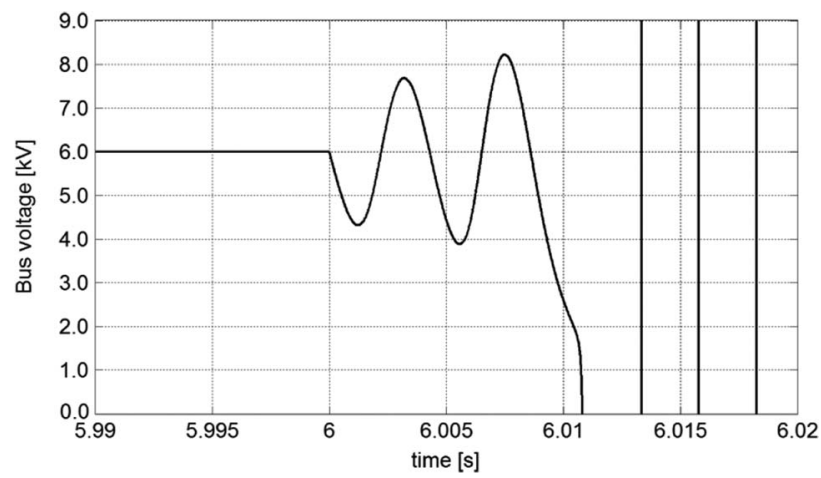

Fig. 27. Bus voltage transient $\left(f_{l}\right.$ off, $f_{c}$ on). 


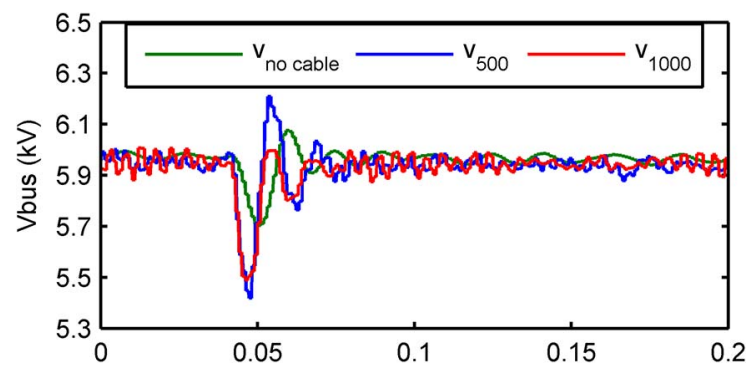

Fig. 28. Load increase from 20 to 45 MW on a 60-MW SPS.

pulse width modulation implementations on the transient behavior, and discuss and validate the assumption of neglecting the longitudinal cable parameters in the control design procedure. Fig. 28 shows that for cable lengths exceeding a certain limit, stability is not impaired.

\section{F. Combination of Active Damping and Linearization via State Feedback}

While LSF gives robust stability to the dc system even in presence of high shares of CPL loads (up to total power), its implementation requires the measurement of several system variables, as well as complex centralized calculation. This threatens the robustness of the stabilization system, because a fault in a sensor or the loss of the centralized controller can bring the system in unstable conditions due to loss of proper control. One of the solutions could be the adoption of a combined AD + LSF control: the LSF control can be applied via the load side directly on the dc/dc converters supplying high power CPL loads, while AD control can be applied via the generation side. The former virtually erases the nonlinear influence of high power CPLs on the system dc bus, while the latter damps oscillations that could occur on the MVDC bus due to disturbances, imperfect CPL cancellation of high power loads, or low power CPLs [104].

With this approach, the LSF implementation requires only local measurements (of high power loads), and acts only on the local converter, avoiding centralized control and fast data transmission throughout the ship. Conversely, the AD requires very little information on the system, in practice only converters output currents, so it can be implemented in a centralized way with very low effort. The combination of the two controls can be done to avoid adverse interactions, thus preserving only the advantages of both.

\section{G. Decentralized Generation Side Approaches}

Load side stabilization techniques are often decentralized as they only act on the local load with limited knowledge of the rest of the system. Here we propose a generation side decentralized control approach, presented in [99]-[102], that does not rely on remote measurements but only on a local system model. Those control approaches are implemented in each generation side interfacing converters.

The system in Fig. 25 can be reduced to the decentralized model depicted in Fig. 30.

The two main components of the linear quadratic Gaussian (LQG) control are the extended Kalman filter (EKF) and the linear quadratic regulator (LQR). They enable decoupling of the response to command signals and disturbances, respectively [99], [100]. The controller follows a two-layer approach: a fast stabilizing control action, and a slower secondary action, which is responsible for the power sharing between the LRCs via droop.

Being decentralized, this LQG controller is local and lacks information of the overall system. Thus, the remote part of the system is modeled by the current source $I_{d_{k}}$, including the currents injected in the bus by nonlocal generators (e.g., $E_{2, \ldots, N}$ ) and the nonlinear loads $I_{\mathrm{CPL}}$.

The model in Fig. 30 leads to a $2 \times 2$ local state-space model. To include the disturbance $I_{d, k}$ in the Kalman filter and estimate it, it is necessary to augment the local model with this variable as an additional state, which results in a $(3 \times 3)$ model. The stochastic state-space model used for the Kalman filter calculation takes the form in

$$
\begin{aligned}
\frac{d}{d t}\left[\begin{array}{c}
I_{k} \\
V \\
I_{d, k}
\end{array}\right]= & {\left[\begin{array}{ccc}
-\frac{R_{f_{k}}}{L_{f_{k}}} & -\frac{1}{L_{f_{k}}} & 0 \\
\frac{1}{C_{f_{k}}} & -\frac{1}{R_{\operatorname{lin}_{k}} \cdot C_{f_{k}}} & -\frac{1}{C_{f_{k}}} \\
0 & 0 & -a_{d_{k}}
\end{array}\right]\left[\begin{array}{c}
I_{k} \\
V \\
I_{d, k}
\end{array}\right] } \\
& \left.+\left[\begin{array}{c}
\frac{1}{L_{f_{k}}} \\
0 \\
u_{k n, k}+ \\
0
\end{array}\right] \begin{array}{c}
0 \\
b_{d_{k}}
\end{array}\right] w_{k} \\
y_{k}= & {\left[\begin{array}{lll}
0 & 1
\end{array}\right]\left[\begin{array}{c}
I_{k} \\
V \\
I_{d, k}
\end{array}\right]+v_{k} . }
\end{aligned}
$$

As the observer estimates one additional state, the twodegree-of-freedom structure is augmented with $L_{\text {ext }}$, a term expressing the online deviation of the system setpoint due to the virtual disturbance. This setpoint trajectory generator is also used to mitigate the deviation between the values of the states of the linearized model and the actual nonlinear values. The overall structure of the controller is presented in Fig. 29.

The LQR part of the LQG controller uses the nonaugmented equations of the system model, assuming no disturbance inputs as defined in [99]. Therefore, the control action is performed considering the values of the 


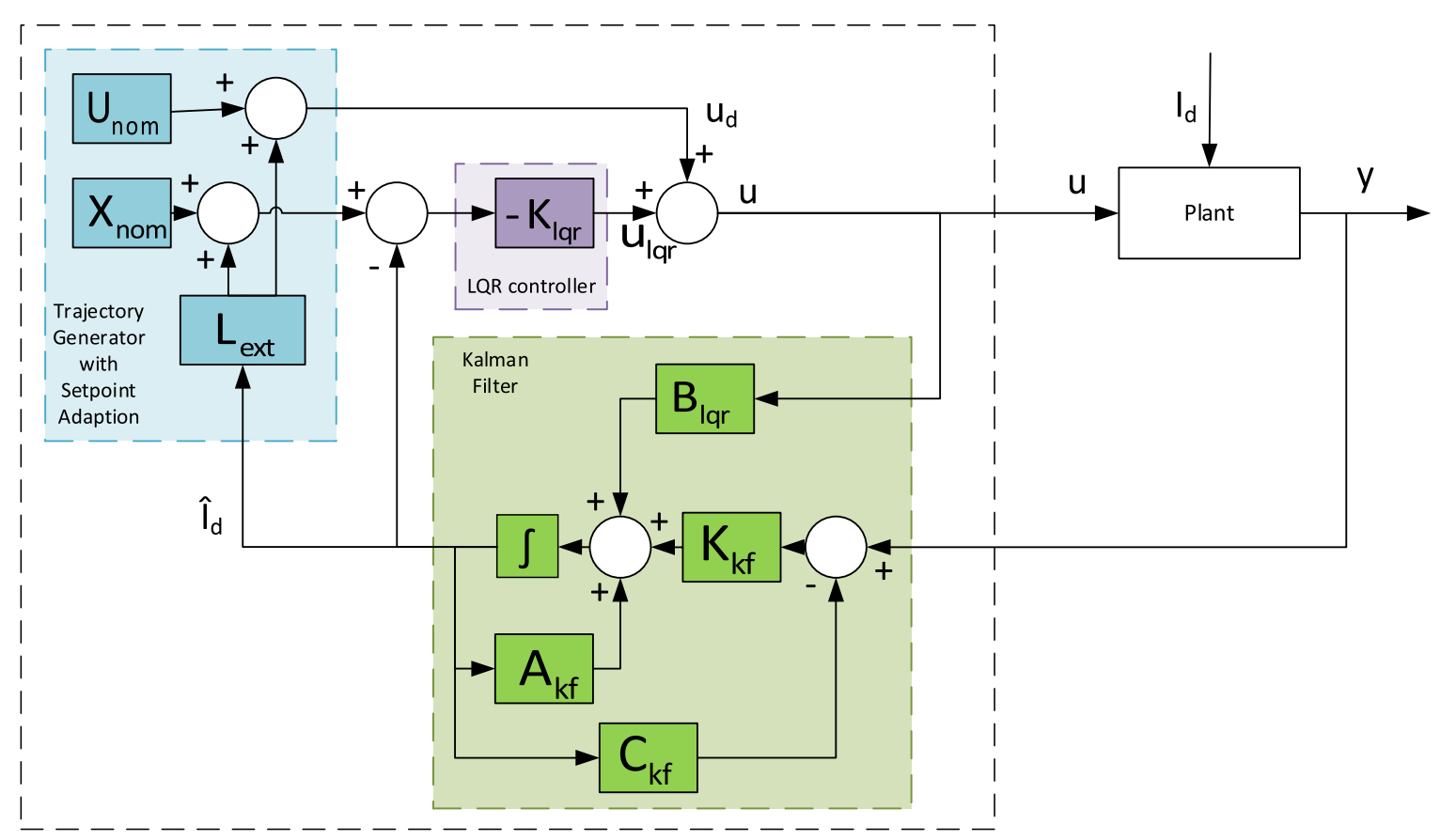

Fig. 29. Structure of the online setpoint adaption LQG controller.

states of the original system, and the possible deviations are already compensated for by the online setpoint adaption. For the full mathematical representation, we refer the reader to [99]-[101]. Figs. 31 and 32 present the transient performance when one of the generation side converters is disconnected. This result indicates that the control architecture is able to overcome large signal disturbances.

A successful hardware implementation of the decentralized control algorithm with only local knowledge is presented in [100] and [101]. In selected test cases, the virtual disturbance model is able to deal with switched systems, which exhibit nonlinear behavior and significant ripple in voltage and current. The HiL implementation and simulation of the controller show that bus voltage stabilization in the presence of large load perturbations (50\% load connection) is guaranteed. The implemented controller is also able to handle changes in the generation in cases where up to $33 \%$ of installed generation capacity is disconnected.

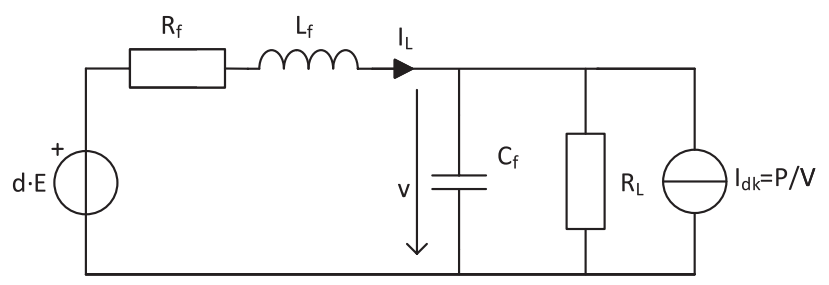

Fig. 30. Decentralized model.
Another way to deal with the influence of the uncertain part of the network is adaptive backstepping, where the parameter estimation is part of the control law design [100], [102]. The overall structure for this design is based on a local state-space model and is schematically shown in Fig. 33.

Starting from a local state-space representation, the following equation is derived according to the model in Fig. 30 where the current of the constant power load is $i_{d}=P / v$ :

$$
\begin{aligned}
& \dot{x}_{1}=\frac{x_{2}}{C_{f}}-\frac{x_{1}}{R_{L} C_{f}}-\frac{P}{x_{1} C_{f}} \\
& \dot{x}_{2}=\frac{d E}{L_{f}}-\frac{x_{2} R_{f}}{L_{f}}-\frac{x_{1}}{L_{f}} .
\end{aligned}
$$

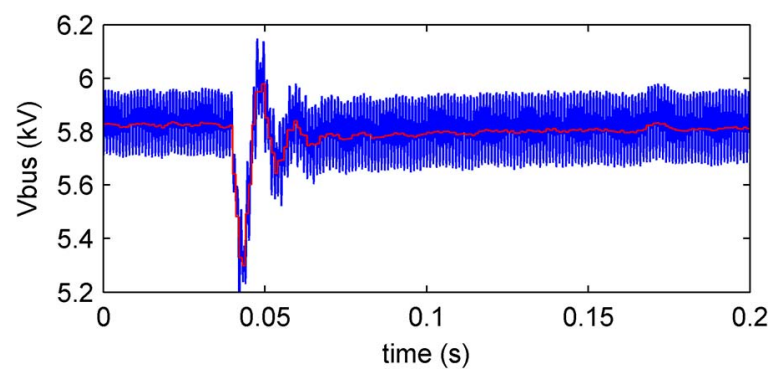

Fig. 31. Converter disconnection: bus voltage. 

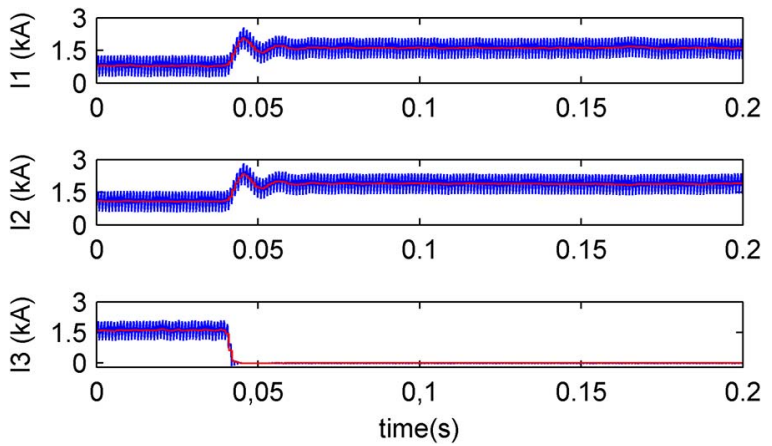

Fig. 32. Converter disconnection: uneven converter currents.

After applying the backstepping procedure and using a Lyapunov function, the duty cycle $d$ is obtained as in

$$
\begin{aligned}
d=\frac{L_{f} C_{f}}{E}\left[\left(c_{1}^{2}-1\right) z_{1}-\left(c_{1}+c_{2}\right) z_{2}\right. \\
+\left(\frac{1}{L_{f} C_{f}}-\frac{1}{R_{L}^{2} C_{f}^{2}}\right) x_{1} \\
+\left(\frac{R_{f}}{L_{f} C_{f}}+\frac{1}{R_{L} C_{f}^{2}}\right) x_{2}+\frac{c_{1} \hat{P}_{2}}{x_{1} C_{f}} \\
\left.\quad-\frac{c_{1} \hat{P}_{1}}{x_{1} C_{f}}-\frac{\hat{P}_{2}}{x_{1} R_{L} C_{f}^{2}}+\frac{\dot{\hat{P}}_{1}}{x_{1} C_{f}}-\frac{\hat{P}_{1}}{x_{1}^{2} C_{f}}\right] \\
\dot{\hat{P}}_{2}=\gamma_{2}\left(-\frac{c_{1} z_{2}}{x_{1} C_{f}}+\frac{z_{2}}{x_{1} R_{L} C_{f}^{2}}\right)
\end{aligned}
$$

where $z_{1,2}$ are error variables, $\hat{P}_{1,2}$ are the power estimates, $\gamma_{1,2}$ are design parameters, and $c_{1,2}$ are the control coefficients. For a detailed explanation of the procedure, the reader is referred to [102]. Figs. 34 and 35 provide a sample of the performance of two backstepping ap-

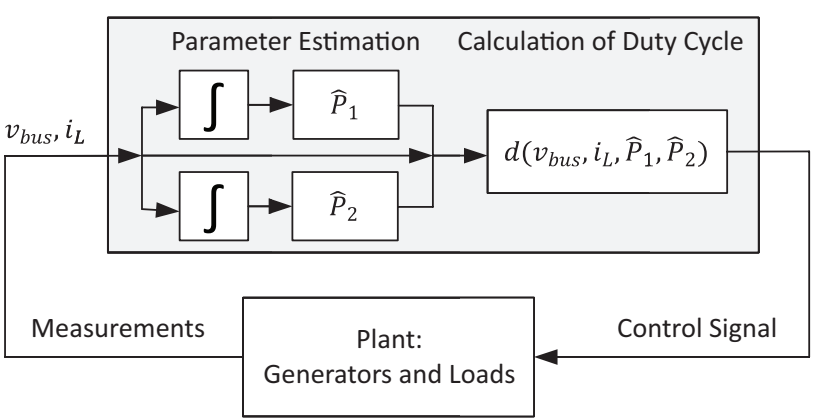

Fig. 33. Structure of the adaptive backstepping controller.

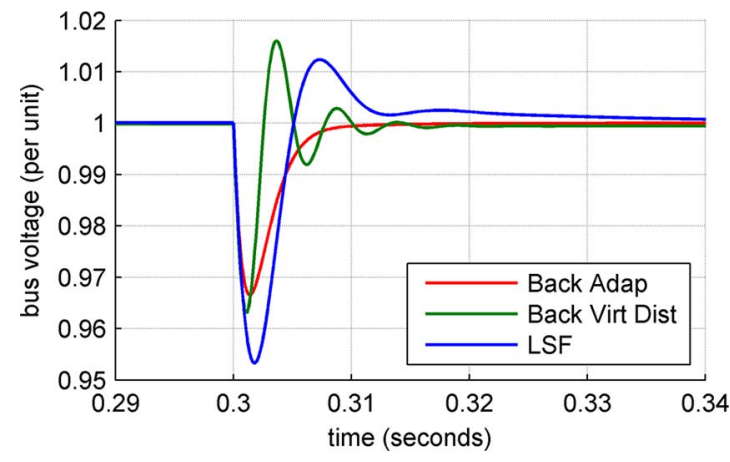

Fig. 34. Bus voltage: Generator loss at $30.9 \mathrm{MW}$.

proaches with the centralized LSF controller. It has to be highlighted that results in Figs. 34 and 35 do not necessarily imply that the backstepping is better or worse than other techniques. They should be interpreted as a qualitative proof that the performance of a decentralized controller is comparable to the performance of a centralized controller, and that MVDC systems can be stabilized in response to larger perturbations effectively by decentralized controllers [102].

\section{CONCLUSION}

This paper presents a broad overview of the state of the art of the automation challenges in ship modern power systems, with emphasis on MVDC architectures.

In order to select the best suited control solution, it is necessary to take into account that changes in network topology would directly influence the suitability of a selected control algorithm. As an example, a full modelbased controller may offer the best performance under regular load changes but may react poorly in the event of a generator loss; therefore, a control algorithm that partitions the power system, without communication infrastructure, may be more suitable in this case.

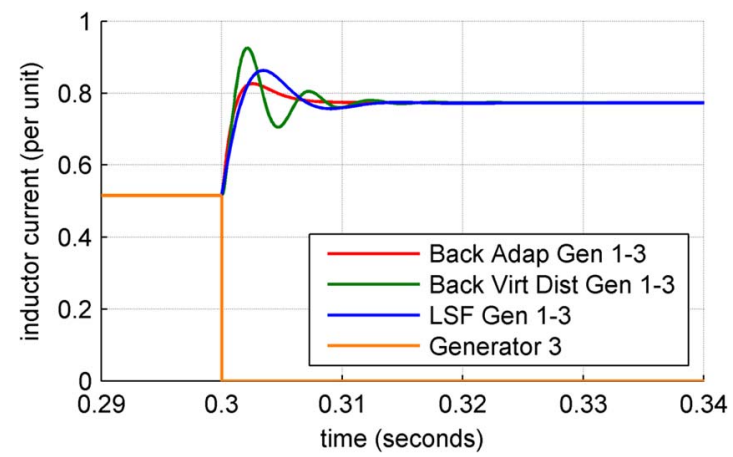

Fig. 35. Inductor currents: Generator loss. 
At high level, the main question is the role of decentralized solutions versus centralized solutions. This paper shows that distributed and decentralized control approaches fulfill the requirements of reconfiguration, and dc bus stability under severe circumstances, and thus offer better fault tolerance increasing survivability. Furthermore, decentralized control approaches are earning ground in terrestrial power system applications, due to the possibility to avoid high bandwidth information communication between the system components, which may be at significant distance in terrestrial systems.

Regarding the faster dynamic induced by pervasive power electronic converters, the main question is the role of the generation side control versus the load side control. One of the main drawbacks of the load side control is that each load needs a special converter, which has to guarantee stability: as a result, the application of commercial off-the-shelf (COTS) components becomes impossible. In fact, each converter should include a special stabilizing control whose region of stability has to be recalculated in case of reconfiguration. Additionally, the number of converters that have to be equipped with a stabilizing action for the generation side control is lower than for the load side control, which facilitates the key technical challenge of bus voltage regulation.

While MVDC distribution in AES is still mostly a concept, the research in this field has sparked virtuous cross fertilization with terrestrial systems. As mentioned in the Introduction, the anticipated development of dc technology for distribution grids is one of the clearest examples.

Furthermore, many of the automation concepts summarized here are finding immediate applications in the design of modern microgrids.

\section{Acknowledgment}

The authors would like to thank M. Paz de Carro, M. Mirz, L. Cupelli, Dr. V. Arcidiacono, Dr. D. Bosich, and Prof. G. Giadrossi for their contributions to this publication.

\section{REFERENCES}

[1] T. Ericsen, Y. Khersonsky, P. Schugart, and P. Steimer, "PEBB - Power electronics building blocks, from concept to reality," in Proc. 3rd IET Int. Conf. Power Electron. Mach. Drives, April 4-6, 2006, pp. 12-16.

[2] T. Ericsen, “"The second electronic revolution' (it's all about control)," in Rec. Conf. Papers Ind. Appl. Soc. 56th Annu. Petroleum Chem. Ind. Conf., Sep. 14-16, 2009, DOI: 10.1109/PCICON.2009. 5297144.

[3] B. Sarlioglu and C. T. Morris, "More electric aircraft: Review, challenges, opportunities for commercial transport aircraft," IEEE Trans. Transp. Electrificat., vol. 1, no. 1, pp. 54-64, Jun. 2015.

[4] A. Monti and F. Ponci, "PEBB standardization for high-level control: A proposal," IEEE Trans. Ind. Electron., vol. 59, no. 10 , pp. 3700-3709, Oct. 2012

[5] R. W. De Doncker, "Power electronic technologies for flexible DC distribution grids," in Proc. Int. Power Electron. Conf., May 18-21, 2014, pp. 736-743.

[6] R. E. Hebner et al., "Technical cross-fertilization between terrestrial microgrids and ship power systems," J. Modern Power Syst. Clean Energy, May 2015, pp. 1-19, DOI: $10.1007 /$ s40565-015-0108-0.

[7] S. Mashayekh and K. L. Butler-Purry, "Security constrained power management system for the NG IPS ships," in Proc. North Amer. Power Symp., Sept. 26-28, 2010, DOI: $10.1109 /$ NAPS.2010.5618954.

[8] M. Weiming, "Development of vessel integrated power system," in Proc. Int. Conf. Electr. Mach. Syst., Aug. 20-23, 2011, DOI: 10.1109/ICEMS.2011.6073291.

[9] A. Monti et al., "Ship power system control: A technology assessment," in Proc. IEEE Electr. Ship Technol. Symp., Jul. 25-27, 2005, pp. 292-297.
[10] A. Feliachi, K. Schoder, S. Ganesh, and H.-J. Lai, "Distributed control agents approach to energy management in electric shipboard power system," in Proc. IEEE Power Eng. Soc. General Meeting, 2006, DOI: 10.1109/PES.2006.1708943.

[11] H. L. Ginn, F. Ponci, and A. Monti, "Multi-agent control of PEBB based power electronic systems," in Proc. IEEE Trondheim PowerTech, Jun. 19-23, 2011, DOI: 10.1109/ PTC.2011.6019443.

[12] A. Deshmukh, F. Ponci, L. Cristaldi, and M. Faifer, "Power-quality index negotiation criterion for power system soft reconfiguration," in Proc. IEEE Instrum. Meas. Technol. Conf., May 1-3, 2007, DOI: 10.1109/IMTC.2007.379166.

[13] E. Kruger, J. Liu, F. Ponci, and A. Monti, "Optimization of task sharing towards multi-agent control of PEBB based power systems," in Proc. IEEE PES Innovative Smart Grid Technol., Jan. 16-20, 2012, DOI: 10.1109/ISGT.2012.6175709.

[14] S. D. J. McArthur et al., "Multi-agent systems for power engineering applications-Part I: Concepts, approaches, technical challenges," IEEE Trans. Power Syst., vol. 22, no. 4, pp. 1743-1752, Nov. 2007.

[15] F. Ponci and H. L. Ginn, "Multi-agent control of PEBB based power electronic systems," in Proc. IEEE Power Energy Soc. General Meeting, Conv. Delivery Electr. Energy 21st Century, Jul. 20-24, 2008, DOI: 10.1109/PES.2008.4596901.

[16] K. Huang, D. A. Cartes, and S. K. Srivastava, "A multiagent-based algorithm for ring-structured shipboard power system reconfiguration," IEEE Trans. Syst. Man Cybern. C, Appl. Rev., vol. 37, no. 5, pp. 1016-1021, Sep. 2007.

[17] S. Chun-Lien, L. Cong-Kai, C. Tso-Chu, and C. Ching-Jin, "Design of a multi-agent system for shipboard power systems restoration," in Proc. IEEE/IAS 50th Ind. Commercial Power Syst. Tech. Conf., May 20-23, 2014, DOI: $10.1109 /$ ICPS.2014.6839164.
[18] S. Srivastava, S. Suryanarayanan, P. Ribeiro, D. Cartes, and M. Stcurer, "A conceptual power quality monitoring technique based on multi-agent systems," in Proc. 37th Annu. North Amer. Power Symp., Oct. 23-25, 2005, pp. 358-363.

[19] F. Berthold, M. Carpita, A. Monti, and F. Ponci, "A multi-agent approach to radial feeder voltage control of PEBB-based converter: A real time simulation test," in Proc. IEEE Energy Conv. Congr. Expo., Sep. 15-20, 2012, pp. 1990-1997.

[20] J. A. Hossack, J. Menal, S. D. J. McArthur, and J. R. Mcdonald, "A multiagent architecture for protection engineering diagnostic assistance," IEEE Trans. Power Syst., vol. 18, no. 2, pp. 639-647, May 2003.

[21] G. Lipardi et al., "Electric loads characterization in an aircraft carrier with ring-bus distribution system," Electrical Systems for Aircraft, Railway and Ship Propulsion (ESARS), Mar. 3-5, 2015.

[22] S. Castellan, R. Menis, M. Pigani, G. Sulligoi, and A. Tessarolo, "Modeling and simulation of electric propulsion systems for all-electric cruise liners," in Proc. IEEE Electr. Ship Technol. Symp., May 21-23, 2007, pp. 60-64.

[23] V. Arcidiacono, R. Menis, and G. Sulligoi, "Improving power quality in all electric ships using a voltage and VAR integrated regulator," in Proc. IEEE Electr. Ship Technol. Symp., May 21-23, 2007, pp. 322-327.

[24] N. Doerry, "Naval power systems: Integrated power systems for the continuity of the electrical power supply," IEEE Electrificat. Mag., vol. 3, no. 2, pp. 12-21, Jun. 2015.

[25] G. Sulligoi et al., "Design, implementation and testing of a shipboard medium-voltage DC generation system based on a ultra-high speed 12-phase alternator," in Proc. IEEE Electr. Ship Technol. Symp., Apr. 10-13, 2011, pp. 388-395.

[26] M. Roa, "ABS rules for integrated power systems (IPS)," in Proc. IEEE Electr. Ship 
Technol. Symp., Apr. 20-22, 2009, DOI: 10.1109/ESTS.2009.4906487.

[27] S. Poroseva, S. Woodruff, and M. Y. Hussaini, "Topology of the generator bus in a warship integrated power system," in Proc. IEEE Electr. Ship Technol. Symp., Jul. 27-27, 2005, pp. 141-148.

[28] C. Patsios, G. Antonopoulos, and J. Prousalidis, "Discussion on adopting intelligent power management and control techniques in integrated power systems of all-electric ships," Electrical Systems for Aircraft, Railway and Ship Propulsion (ESARS), Oct. 16-18, 2012.

[29] J. D. Stevens, D. F. Opila, A. M. Cramer, and E. L. Zivi, "Operational vignette-based electric warship load demand," in Proc. IEEE Electr. Ship Technol. Symp., Jun. 21-24, 2015, pp. 213-218.

[30] R. Jayabalan and B. Fahimi, "Fault diagnostics in naval shipboard power system for contingency management and survivability," in Proc. IEEE Electr. Ship Technol. Symp., Jul. 27-27, 2005, pp. 108-111.

[31] A. Tessarolo, S. Castellan, R. Menis, and G. Sulligoi, "Electric generation technologies for all-electric ships with medium-voltage DC power distribution systems," in Proc. IEEE Electr. Ship Technol. Symp. Apr. 22-24, 2013, pp. 275-281.

[32] IEEE Recommended Practice for $1 \mathrm{kV}$ to $35 \mathrm{kV}$ Medium-Voltage DC Power Systems on Ships, IEEE Std 1709-2010, Nov. 2, 2010, pp. 1-54.

[33] P. Kundur et al., "Definition and classification of power system stability IEEE/ CIGRE joint task force on stability terms and definitions," IEEE Trans. Power Syst., vol. 19, no. 3, pp. 1387-1401, Aug. 2004.

[34] P. Kundur, Power System Stability and Control. New York, NY, USA: McGraw-Hill, 1994.

[35] R. Marconato, "Electric power systems," CEI-Italian electro technical committee, 2008, vol. 3, Dynamic Behaviour, Stability and Emergency Controls.

[36] F. P. Demello and C. Concordia, "Concepts of synchronous machine stability as affected by excitation control," IEEE Trans. Power Apparatus Syst., vol. PAS-88, no. 4, pp. 316-329, Apr. 1969.

[37] S. D. Sudhoff and J. M. Crider, "Advancements in generalized immittance based stability analysis of DC power electronics based distribution systems," in Proc. IEEE Electr. Ship Technol. Symp., Apr. 10-13, 2011, pp. 207-212.

[38] P. C. Krause, Analysis of Electric Machinery. New York, NY, USA: McGraw-Hill, 1986.

[39] P. C. Krause, "Method of multiple reference frames applied to the analysis of symmetrical induction machinery," IEEE Trans. Power Apparatus Syst., vol. 87, no. 1, pp. 227-234, Jan. 1968.

[40] W. G. Heffron and R. A. Phillips, "Effect of a modern amplidyne voltage regulator on underexcited operation of large turbine generators," Trans. Amer. Inst. Electr. Eng. Power Apparatus Syst. III, vol. 71, no. 1, Jan. 1952, DOI: 10.1109/AIEEPAS.1952. 4498530.

[41] V. Arcidiacono, E. Ferrari, and F. Saccomanno, "Studies on damping of electromechanical oscillations in multimachine systems with longitudinal structure," IEEE Trans. Power Apparatus Syst., vol. PAS-95, no. 2, pp. 450-460, Mar./Apr. 1976.
[42] V. Arcidiacono, E. Ferrari, R. Marconato, J. D. Ghali, and D. Grandez, "Evaluation and improvement of electromechanical oscillation damping by means of eigenvalue-eigenvector analysis. Practical results in the central Peru power system," IEEE Trans. Power Apparatus Syst., vol. PAS-99, no. 2, pp. 769-778, Mar./Apr. 1980

[43] G. Sulligoi, A. Vicenzutti, M. Chiandone, D. Bosich, and V. Arcidiacono, "Generators electromechanical stability in shipboard grids with symmetrical layout: Dynamic interactions between voltage and frequency controls," in Proc. AEIT Annu. Conf., Oct. 3-5, 2013, DOI: 10.1109/AEIT.2013.6666812.

[44] G. Giadrossi, R. Menis, G. Sulligoi, and A. Tessarolo, "Voltage stability analysis of all-electric cruise liners," in Proc. Int. Symp. Power Electron. Electr. Drives Autom. Motion, Jun. 11-13, 2008, pp. 586-590.

[45] A. Emadi, "Modelling of power electronic loads in AC distribution systems using the generalized state space averaging method," in Proc. 27th Annu. Conf. IEEE Ind. Electron. Soc., 2001, vol. 2, pp. 1008-1014.

[46] G. Sulligoi, A. Vicenzutti, V. Arcidiacono, and Y. Khersonsky, "Voltage stability in large marine integrated electrical and electronic power systems," in Proc. IEEE Petroleum Chem. Ind. Tech. Conf., 2015, pp. 1-10.

[47] A. Emadi, B. Fahimi, and M. Ehsani, "On the concept of negative impedance instability in the more electric aircraft power systems with constant power loads," SAE J., 1999, DOI: 10.4271/1999-01-2545.

[48] A. Emadi, A. Khaligh, C. H. Rivetta, and G. A. Williamson, "Constant power loads and negative impedance instability in automotive systems: Definition, modeling, stability, control of power electronic converters and motor drives," IEEE Trans. Veh. Technol. vol. 55, no. 4, pp. 1112-1125, Jul. 2006.

[49] V. Arcidiacono, A. Monti, and G. Sulligoi, "Generation control system for improving design and stability of medium-voltage DC power systems on ships," IET Electr. Syst. Transp., vol. 2, no. 3, pp. 158, 167, Sep. 2012.

[50] A. M. Rahimi and A. Emadi, "Active damping in $\mathrm{DC} / \mathrm{DC}$ power electronic converters: A novel method to overcome the problems of constant power loads," IEEE Trans. Ind. Electron., vol. 56, no. 5, pp. 1428-1439, May 2009.

[51] M. Cupelli, L. Zhu, and A. Monti, "Why ideal constant power loads are not the worst case condition from a control standpoint," IEEE Trans. Smart Grid, DOI: 10.1109/TSG.2014. 2361630.

[52] S. D. Sudhoff, "Admittance space based stability specification," in Proc ONR_Drexel-NSWC Workshop Electr. Shipboard Syst. Model. Simul. Control, Philadelphia, PA, USA, Jun. 22-23, 1998.

[53] A. Riccobono and E. Santi, "Comprehensive review of stability criteria for DC distribution systems," in Proc. IEEE Energy Conv. Congr. Expo., Sep. 15-20, 2012, pp. 3917-3925.

[54] A. Griffo, J. Wang, and D. Howe, "Large signal stability analysis of DC power systems with constant power loads," in Proc. IEEE Veh. Power Propul. Conf., Sep. 3-5, 2008, DOI: $10.1109 /$ VPPC.2008.4677551.

[55] S. Grillo, V. Musolino, G. Sulligoi, and E. Tironi, "Stability enhancement in DC distribution systems with constant powe controlled converters," in Proc. IEEE 15th Int. Conf. Harmonics Quality of Power, Jun. 17-20, 2012, pp. 848-854.
[56] D. Bosich, G. Giadrossi, G. Sulligoi, S. Grillo, and E. Tironi, "More electric vehicles DC power systems: A large signal stability analysis in presence of CPLs fed by floating supply voltage," in Proc. IEEE Int. Electr. Veh. Conf., Dec. 17-19, 2014, DOI: 10.1109/IEVC. 2014.7056226.

[57] D. Marx, P. Magne, B. Nahid-Mobarakeh, S. Pierfederici, and B. Davat, "Large signal stability analysis tools in DC power systems with constant power loads and variable power loads-A review," IEEE Trans. Power Electron., vol. 27, no. 4, pp. 1773-1787, Apr. 2012.

[58] M. Cespedes, T. Beechner, L. Xing, and J. Sun, "Stabilization of constant power loads by passive impedance damping," in Proc. 25th Annu. IEEE Appl. Power Electron. Conf. Expo. 2010, pp. 2174-2180.

[59] A.-B. Awan, S. Pierfederici, B. Nahid-Mobarakeh, and F. Meibody-Tabar, "Active stabilization of a poorly damped input filter supplying a constant power load," in Proc. IEEE Energy Conv. Congr. Expo., Sep. 20-24, 2009, pp. 2991-2997.

[60] A.-B. Awan, B. Nahid-Mobarakeh, S. Pierfederici, and F. Meibody-Tabar, "Nonlinear stabilization of a DC-bus supplying a constant power load," in Proc Ind. Appl. Soc. Annu. Meeting, Oct. 4-8, 2009, DOI: 10.1109/IAS.2009.5324842.

[61] X. Liu, A. Forsyth, and A. Cross, "Negative input-resistance compensator for a constant power load," IEEE Trans. Ind. Electron. vol. 54, no. 6, pp. 3188-3196, 2007.

[62] W.-J. Lee and S.-K. Sul, "DC-link voltage stabilization for reduced DC-link capacitor inverter," IEEE Trans. Ind. Appl., vol. 50, no. 1, pp. 404-414, Jan.-Feb. 2014.

[63] P. Liutanakul, A.-B. Awan, S. Pierfederici, B. Nahid-Mobarakeh, and F. Meibody-Tabar, "Linear stabilization of a DC bus supplying a constant power load: A general design approach," IEEE Trans. Power Electron., vol. 25, no. 2, pp. 475-488, Feb. 2010.

[64] K. Sun, L. Zhang, Y. Xing, and J. Guerrero, "A distributed control strategy based on DC bus signaling for modular photovoltaic generation systems with battery energy storage," IEEE Trans. Power Electron., vol. 26 no. 10, pp. 3032-3045, Oct. 2011.

[65] T. L. Vandoorn, B. Renders, L. Degroote, B. Meersman, and L. Vandevelde, "Power balancing in islanded microgrids by using a dc-bus voltage reference," in Proc. Int. Symp. Power Electron. Electr. Drives Autom. Motion, 2010, pp. 884-889.

[66] V. N. Chuvychin, N. S. Gurov, S. S. Venkata, and R. E. Brown, "An adaptive approach to load shedding and spinning reserve control during underfrequency conditions," IEEE Trans. Power Syst., vol. 11, no. 4 pp. 1805-1810, Nov. 1995.

[67] C. W. Taylor, "Concepts of undervoltage load shedding for voltage stability," IEEE Trans. Power Delivery, vol. 7, no. 2, pp. 480-488, Apr. 1992.

[68] A. Saffarian and M. Sanaye-Pasand, "Enhancement of power system stability using adaptive combinational load shedding methods," IEEE Trans. Power Syst., vol. 26, no. 3, pp. 1010-1020, Aug. 2011.

[69] H. Seyedi and M. Sanaye-Pasand, "New centralised adaptive load-shedding algorithms to mitigate power system blackouts," IET Generat. Transm. Distrib., vol. 3, no. 1, pp. 99-114, Jan. 2009.

[70] K. Seethalekshmi, S. N. Singh, and S. C. Srivastava, "Asynchrophasor assisted frequency and voltage stability based load 
shedding scheme for self-healing of power system," IEEE Trans. Smart Grid, vol. 2, no. 2 pp. 221-230, Jun. 2011.

[71] J. Tang, J. Liu, F. Ponci, and A. Monti, "Adaptive load shedding based on combined frequency and voltage stability assessment using synchrophasor measurements," IEEE Trans. Power Syst., vol. 28, no. 2 , pp. 2035-2047, May 2013.

[72] M. Adamiak, M. J. Schiefen, G. Schauerman, and B. Cable, "Design of a priority-based load shed scheme and operation tests," IEEE Trans. Ind. Appl., vol. 50, no. 1, pp. 182-187, Jan.-Feb. 2014.

[73] R. S. Balog, W. W. Weaver, and P. T. Krein, "The load as an energy asset in a distributed DC smartgrid architecture," IEEE Trans. Smart Grid, vol. 3, no. 1, pp. 253-260, Mar. 2012.

[74] D. Zhiping, S. Srivastava, and D. Cartes, "Expert system based dynamic load shedding scheme for shipboard power systems," in Conf. Rec. IEEE Ind. Appl. Conf., Oct. 8-12, 2006, vol. 3, pp. 1338-1344.

[75] D. Zhiping, S. K. Srivastava, D. A. Cartes, and S. Suryanarayanan, "Dynamic simulation based analysis of a new load shedding scheme for a notional destroyer class shipboard power system," in Proc. IEEE Electr. Ship Technol. Symp., May 21-23, 2007, pp. 95-102.

[76] T. L. Saaty, The Analytic Hierarchy Process. New York, NY, USA: McGraw-Hill, 1980.

[77] J. Z. Zhu and M. R. Irving, "Combined active and reactive dispatch with multiple objectives using an analytic hierarchical process," Inst. Electr. Eng. Proc.-Generat. Transmission . Distrib., vol. 143, no. 4, pp. 344-352, Jul. 1996.

[78] D. Zhiping, S. K. Srivastava, D. A. Cartes, and S. Suryanarayanan, "Dynamic simulation-based analysis of a new load shedding scheme for a notional destroyer-class shipboard power system," IEEE Trans. Ind. Appl., vol. 45, no. 3, pp. 1166-1174, May./Jun. 2009.

[79] Multilogic, Exsys Developer User Manual, Version 8.1.9, 1999

[80] J. Langston et al., "Experiences with the simulation of a notional all-electric ship integrated power system on a large-scale high-speed electromagnetic transient simulator," in Proc. IEEE Power Eng. Soc. Gen. Meeting, Jun. 18-22, 2006, DOI: 10.1109/PES.2006.1709224.

[81] A. Ouroua, L. Domaschk, and J. H. Beno, "Electric ship power system integration analyses through modeling and simulation," in Proc. IEEE Electr. Ship Technol. Symp. Jul. 27-27, 2005, pp. 70-74.

[82] V. Salehi, B. Mirafzal, and O. Mohammed, "Pulse-load effects on ship power system stability," in Proc. 36th Annu. Conf. IEEE Ind. Electron. Soc., Nov. 7-10, 2010 pp. 3353-3358.

[83] D. Gadoura et al., "Stabilizing a telecom power supply feeding a constant power load," in Proc. 20th Int. Telecommun. Energy Conf., 1998, pp. 243-248.
[84] J. G. Ciezki and R. W. Ashton, "The application of feedback linearization techniques to the stabilization of DC-to-DC converters with constant power loads," in Proc. IEEE Int. Symp. Circuits Syst., May 31-Jun. 3 1998, vol. 3, pp. 526-529.

[85] S. R. Sanders and G. C. Verghese, "Lyapunov-based control for switched power converters," IEEE Trans. Power Electron., vol. 7, no. 1, pp. 17-24, Jan. 1992.

[86] G. Sulligoi, D. Bosich, and G. Giadrossi, "Linearizing voltage control of MVDC power systems feeding constant power loads: Stability analysis under saturation," in Proc. IEEE Power Energy Soc. Gen. Meeting, Jul. 21-25, 2013, DOI: 10.1109/PESMG. 2013.6672966

[87] A. Kwasinski and P. T. Krein, "Stabilization of constant power loads in Dc-Dc converters using passivity-based control," in Proc. 29th Int. Telecommun. Energy Conf., Sep. 30-Oct. 4 2007, pp. 867-874.

[88] C. H. Rivetta, A. Emadi, G. A. Williamson, R. Jayabalan, and B. Fahimi, "Analysis and control of a buck DC-DC converter operating with constant power load in sea and undersea vehicles," IEEE Trans. Ind. Appl., vol. 42, no. 2, pp. 559-572, Mar./Apr. 2006.

[89] A. M. Rahimi, G. A. Williamson, and A. Emadi, "Loop-cancellation technique: A novel nonlinear feedback to overcome the destabilizing effect of constant-power loads," IEEE Trans. Veh. Technol., vol. 59, no. 2, pp. 650-661, Feb. 2010.

[90] Y. Zhao and W. Qiao, “A third-order sliding-mode controller for DC/DC converters with constant power loads," in Proc. IEEE Ind. Appl. Soc. Annu. Meeting, Oct. 9-13, 2011, DOI: 10.1109/IAS.2011.6074347.

[91] C. N. Onwuchekwa and A. Kwasinski, "Analysis of boundary control for buck converters with instantaneous constant-power loads," IEEE Trans. Power Electron., vol. 25, no. 8, pp. 2018-2032, Aug. 2010.

[92] A. Kwasinski and C. N. Onwuchekwa, "Dynamic behavior and stabilization of $\mathrm{dc}$ microgrids with instantaneous constantpower loads," IEEE Trans. Power Electron. vol. 26, no. 3, pp. 822-834, Mar. 2011.

[93] I. Kondratiev and R. Dougal, "Synergetic control strategies for shipboard DC power distribution systems," in Proc. Amer. Control Conf., Jul. 9-13, 2007, pp. 4744-4749.

[94] I. Kondratiev, E. Santi, R. Dougal, and G. Veselov, "Synergetic control for DC-DC buck converters with constant power load," in Proc. IEEE 35th Annu. Power Electron. Specialists Conf., Jun. 20-25, 2004, vol. 5, pp. 3758-3764.

[95] I. Kondratiev, E. Santi, R. Dougal, and G. Veselov, "Synergetic control for m-parallel connected DC-DC buck converters," in Proc. IEEE 35th Annu. Power Electron. Specialists Conf., Jun. 20-25, 2004 vol. 1, pp. 182-188.

[96] A. Vicenzutti, D. Bosich, and G. Sulligoi, "MVDC power system voltage contro through feedback linearization technique: Application to different shipboard power conversion architectures," in Proc. IEEE
Electr. Ship Technol. Symp., Apr. 22-24, 2013, pp. 303-307.

[97] A. Khaligh, "Realization of parasitics in stability of DC-DC converters loaded by constant power loads in advanced multiconverter automotive systems," IEEE Trans. Ind. Electron., vol. 55, no. 6, pp. 2295-2305, Jun. 2008.

[98] A. Khaligh, A. M. Rahimi, and A. Emadi, "Modified pulse-adjustment technique to control DC/DC converters driving variable constant-power loads," IEEE Trans. Ind. Electron., vol. 55, no. 3, pp. 1133-1146, Mar. 2008.

[99] L. Zhu, J. Liu, M. Cupelli, and A. Monti, "Decentralized linear quadratic Gaussian control of multi-generator MVDC shipboard power system with constant power loads," in Proc. IEEE Electr. Ship Technol. Symp., Apr. 22-24, 2013, pp. 308-313.

[100] M. Cupelli, "Advanced control methods for robust stability of MVDC systems," Ph.D. dissertation, RWTH Aachen Univ., Aachen, Germany, 2015.

[101] M. Cupelli, M. de Paz Carro, and A. Monti, "Hardware in the loop implementation of a disturbance based control in MVDC grids," in Proc. IEEE Power Energy Soc. Gen. Meeting, July 26-30, 2015, DOI: 10.1109/PESGM. 2015.7285773.

[102] M. Cupelli, M. M. Mirz, and A. Monti, "Application of backsteppping to MVDC ship power systems with constant power loads," in Proc. Electr. Syst. Aircraft Railway Ship Propulsion Road Veh., Mar. 3-5, 2015, DOI: 10.1109/ESARS.2015.7101469.

[103] G. Sulligoi, D. Bosich, L. Zhu, M. Cupelli, and A. Monti, "Linearizing control of shipboard multi-machine MVDC power systems feeding constant power loads," in Proc. IEEE Energy Conv. Congr. Expo. Sep. 15-20, 2012, pp. 691-697.

[104] G. Sulligoi, D. Bosich, V. Arcidiacono, and G. Giadrossi, "Considerations on the design of voltage control for multi-machine MVDC power systems on large ships," in Proc. IEEE Electr. Ship Technol. Symp., Apr. 22-24, 2013, pp. 314-319.

[105] G. Sulligoi et al., "Multiconverter medium voltage DC power systems on ships: Constant-power loads instability solution using linearization via state feedback control," IEEE Trans. Smart Grid, vol. 5, no. 5, pp. 2543-2552, Sep. 2014.

[106] M. Cupelli, M. de Paz Carro, and A. Monti, "Hardware in the loop implementation of linearizing state feedback on MVDC ship systems and the significance of longitudinal parameters," in Proc. Electr. Syst. Aircraft Railway Ship Propulsion Road Veh., Mar. 3-5, 2015, DOI: 10.1109/ESARS.2015.7101470.

[107] M. Cupelli, M. Moghimi, A. Riccobono, and A. Monti, "A comparison between synergetic control and feedback linearization for stabilizing MVDC microgrids with constant power load," in Proc. IEEE PES Innovative Smart Grid Technol. Conf. Eur., Oct. 12-15, 2014, DOI: 10.1109/ ISGTEurope.2014.7028870. 


\section{ABOUT THE AUTHORS}

Marco Cupelli received the Diplom Wirt-Ing from the Technische Universität Darmstadt, Darmstadt, Germany, in 2008.

He then worked for a consulting company. He has been a Research Associate in the Institute of Automation of Complex Power Systems, E.ON Energy Research Center, RWTH Aachen University, Aachen, Germany, since 2009. His current research interests include stability issues in distribution networks, microgrids, and dc networks.

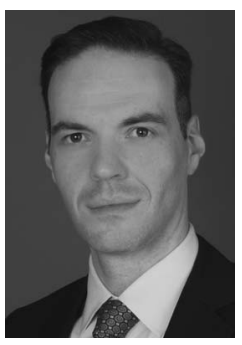

Ferdinanda Ponci (Senior Member, IEEE) received the M.S. and Ph.D. degrees in electrical engineering from Politecnico di Milano, Milan, Italy, in 1998 and 2002, respectively.

She was with the Power and Energy Research Group, Department of Electrical Engineering, University of South Carolina, Columbia, SC, USA, in 2003, as an Assistant Professor, and was tenured and promoted as an Associate Professor in 2008. In 2009, she was with the Institute for

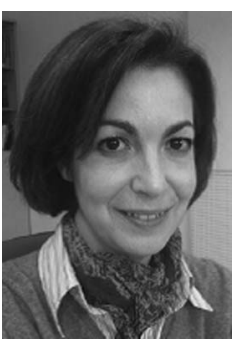
Automation of Complex Power Systems, E.ON Research Center, RWTH Aachen University, Aachen, Germany, where she is currently a Professor. Her current research interests include monitoring and control of distribution systems with pervasive presence of renewables, and application of intelligent agents to energy systems.

Dr. Ponci is a member of the Administration Committee of the IEEE Instrumentation and Measurement Society.

Giorgio Sulligoi (Senior Member, IEEE) received the M.S. degree (with honors) in electrical engineering from the University of Trieste, Trieste, Italy, in 2001 and the Ph.D. degree in electrical engineering from the University of Padua, Padova, Italy, in 2005.

He spent an internship at Fincantieri Electric Systems Office, Trieste, Italy, and a semester as a Visiting Scholar at the University College of Cork, Ireland. In 2005, he joined MAI Control Systems,

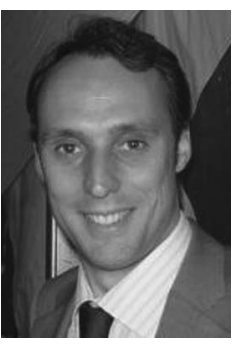
Milan, Italy, an Italian firm operating in the field of power stations and alternator voltage control systems. He joined the University of Trieste in 2007 as an Assistant Professor of Electric Power Generation and Control, tenured since 2010 and was appointed an Assistant Professor of Shipboard Electrical Power Systems in 2012. He is the founder and Director of the grid connected \& marine Electric Power Generation and Control laboratory (EPGC Laboratory) at the Department of Engineering and Architecture. In 2013, he received the national qualification for the level of the Associate Professor in Electrical Energy Engineering. He authored more than 70 scientific papers in the fields of shipboard power systems, all-electric ships, generator modeling, and voltage control.

Dr. Sulligoi is a member of the IEEE Industry Applications Society (IAS), the IEEE Power Electronics Society (PELS), and the IEEE Power and Engineering Society (PES), where he serves in different technical and standard committees.

Andrea vicenzutti (Student Member, IEEE) received the M.Sc. degree (honors) in electrical engineering from the University of Trieste, Trieste, Italy, in 2012. Currently, he is working toward the Ph.D. degree at the University of Padua, Padova, Italy.

$\mathrm{His}$ research activity is on marine power system integration and dependability, and is carried out at the Electric Power Generation and Control Laboratory, Department of Engineering and Architecture (DIA), University of Trieste.
Chris S. Edrington (Senior Member, IEEE) received the B.S. degree in engineering from Arkansas State University, Jonesboro, AR, USA, in 1999 and the M.S. and Ph.D. degrees in electrical engineering from the Missouri Science and Technology (formerly University of MissourivRolla), Rolla, MO, USA, in 2001 and 2004, respectively.

He was both a GAANN and IGERT fellow at the Missouri Science and Technology. From 2004 to 2007, he was an Assistant Professor of Electrical

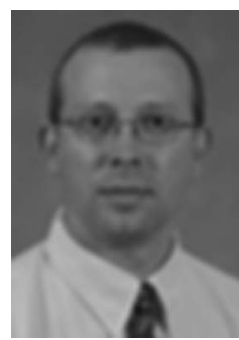
Engineering in the College of Engineering, Arkansas State University. Currently, he is an Associate Professor of Electrical and Computer Engineering with the College of Engineering, Florida A\&M University/ Florida State University (FAMU-FSU), Tallahassee, FL, USA, and is the lead for the Energy Conversion and Integration thrust for the Center for Advanced Power Systems, Florida State University. Additionally, he is the Florida State University Campus Director for the FREEDM Systems NSFERC and the Associate Director for Florida State University's Center for Advanced Power Systems. His research interests include modeling, simulation, and control of electromechanical drive systems; applied power electronics; distributed control; and integration of renewable energy, storage, and pulse power loads.

Touria El-Mezyani (Member, IEEE) received the Ph.D. degree in control, computer and systems engineering from Université des Sciences et Technologies de Lille, Villeneuve d'Ascq, France, in 2005.

She is currently a Research Faculty with the Center for Advanced Power Systems, Florida State University, Tallahassee, FL, USA. Her research interests include complex and hybrid systems application to power systems; distributed/ decen-

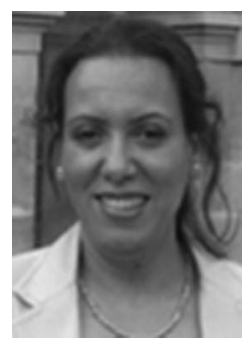
tralized controls and optimization; fault detection, isolation, and diagnosis; control and optimization; and multiagent systems.

Dr. El-Mezyani has been an affiliate member of the IEEE Automatic Control Society since 2008.

Antonello Monti (Senior Member, IEEE) received the M.Sc. degree (summa cum laude) and the Ph.D. degree in electrical engineering from Politecnico di Milano, Milan, Italy, in 1989 and 1994, respectively.

He started his career in Ansaldo Industria and then became an Assistant Professor at Politecnico di Milano in 1995. In 2000, he joined the Department of Electrical Engineering, University of South Carolina, Columbia, SC, USA, as an Associate and

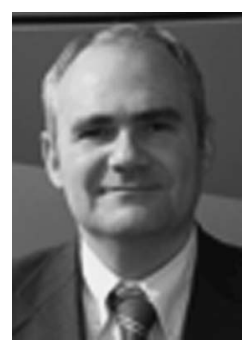
then Full Professor. Since 2008, he has been the Director of the Institute for Automation of Complex Power System within the E.ON Energy Research Center, RWTH Aachen University, Aachen, Germany. He is author or coauthor of more than 200 peer-reviewed papers published in international journals and in the proceedings of international conferences.

Dr. Monti is an Associate Editor of the IEEE SYSTEM JOURNAL. 